Portland State University

PDXScholar

$5-13-1980$

\title{
Art Therapy as a Mechanism for Increasing Life Satisfaction in Later Life
}

Phyllis Laulainen McGraw

Portland State University

Follow this and additional works at: https://pdxscholar.library.pdx.edu/open_access_etds

Part of the Art Therapy Commons, and the Psychology Commons Let us know how access to this document benefits you.

\section{Recommended Citation}

McGraw, Phyllis Laulainen, "Art Therapy as a Mechanism for Increasing Life Satisfaction in Later Life" (1980). Dissertations and Theses. Paper 3048.

https://doi.org/10.15760/etd.3042

This Thesis is brought to you for free and open access. It has been accepted for inclusion in Dissertations and Theses by an authorized administrator of PDXScholar. Please contact us if we can make this document more accessible: pdxscholar@pdx.edu. 
AN ABSTRACT OF THE THESIS OF Phyllis Laulainen MCGraw for the Master of Science in Psychology presented May 13, 1980.

Title: Art Therapy as a Mechanism for Increasing Life Satisfaction in Later Life.

APPROVED BY MEMBERS OF THE THESIS COMMITTEE:

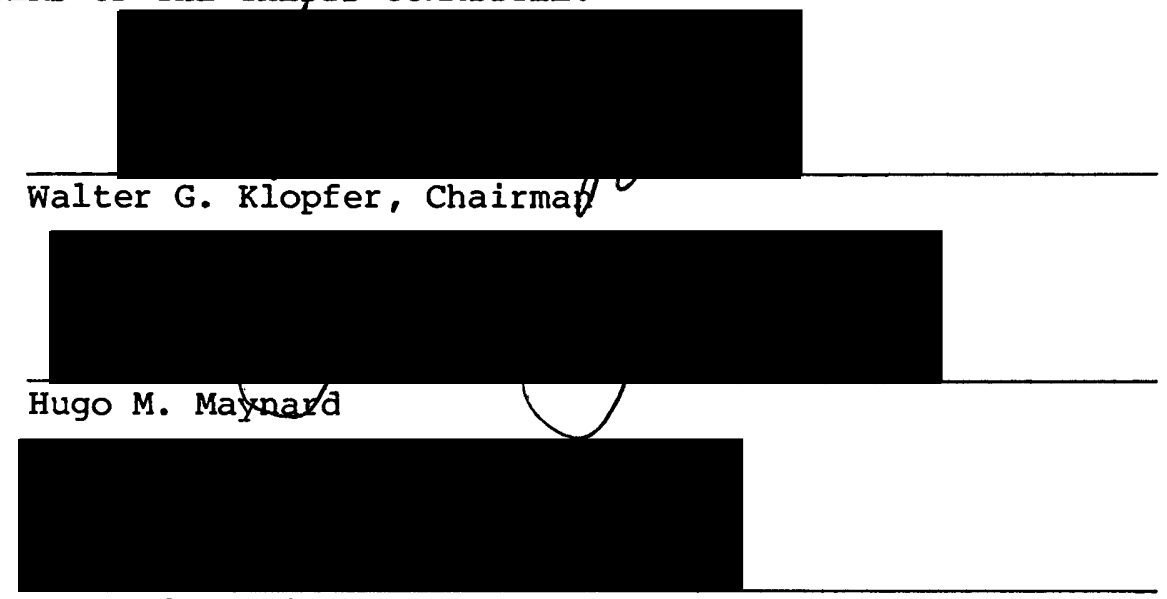

Leonard D Cain

It was hypothesized that art therapy with the elderly would increase the quality of an informal life review and motivate them toward greater psychological well-being (life satisfaction). To test this hypothesis, 30 subjects between the ages of 61 and 83 were assigned to three experimental conditions: Art Therapy Group, Discussion Group, and Control Group.

Most of the differences between the three groups were statistically non-significant in the improvement of life satisfaction as measured on the Life Satisfaction Index-A (LSIA). However, in comparing the Art Therapy Group with the Control Group, the Mann-Whitney was 
significant when using a one-tailed test. These results suggest that both groups, Art Therapy and Discussion, had improvement in LSIA between pre- and post-test scores and that both groups are viable techniques for increasing psychological well-being in later life.

The qualitative results suggest this thesis offers an alternative to addressing the issue of how to improve the quality of later life. It appears that the group interaction in both the Art Therapy Group and Discussion Group did promote greater psychological well-being. It also appears that social interaction, whether in the Art Therapy Group or Discussion Group, may be the primary medium through which a person comes to know himself/herself.

The study was successful not only in improving introspection and fostering a better acceptance of self by people in later life, but the author had the opportunity to develop and test a therapeutic strategy. 


\title{
ART THERAPY AS A MECHANISM FOR INCREASING \\ LIFE SATISFACTION IN LATER LIFE
}

\section{by}

PHYLLIS LAULAINEN MCGRAW

A thesis submitted in partial fulfillment of the requirements for the degree of

\author{
MASTER OF SCIENCE \\ in \\ PSYCHOLOGY
}

Portland State University 
TO THE OFFICE OF GRADUATE STUDIES AND RESEARCH:

The members of the Committee approve the thesis of Phyllis Laulainen McGraw presented May 13, 1980.

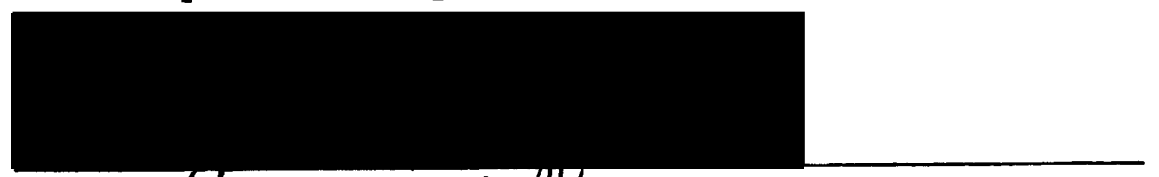

Walter G. Klopfer, Chairmdd

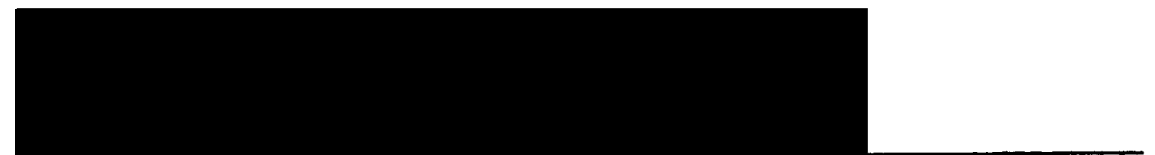

Hugo M. Maynged

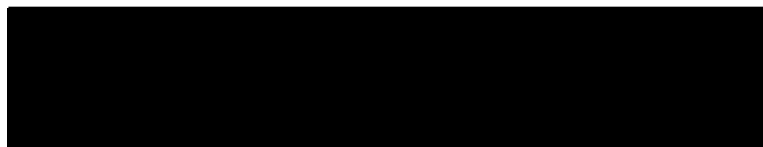

Leonard D Cain

APPROVED:

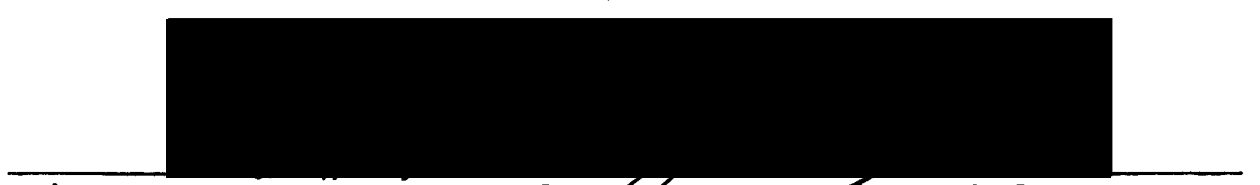

Robert E. Jones, Jr., Head, Department of Psychology

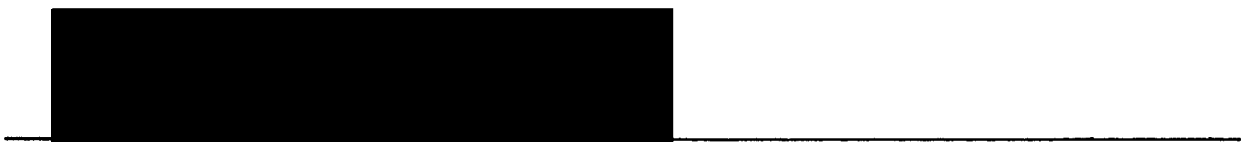

Stanley E. Rauchr, Dean of Graduate Studies and Research 


\section{ACKNOWLEDGMENTS}

The search for knowlege and truth can be a lonely journey without the guidance, encouragement, faith, tolerance, and love of faculty, mentors, co-graduate students, friends, and family. In whatever way this research succeeds in providing people in later life an alternative in coping with the problems of aging, it is due to the many people who have inspired and helped me along the way.

I would like to express a special appreciation to Dr. Walter G. Klopfer, my Advisor and Thesis Chairperson, for the valuable guidance he has provided in the execution of this study and in the preparation of this thesis. Committee members, Dr. Hugo Maynard and Dr. Leonard Cain, each deserve recognition for helping me keep the final writing within its proper perspective. While Dr. James Paulson was not on my committee, I would like to thank him for his assistance with the statistical analysis utilized in this study. Dr. Barbara Stewart deserves special mention, as it was she who first listened to my idea and enthusiastically encouraged me to pursue my dream. Also, Dr. Gerald Murch deserves special mention. In the genesis of this thesis, he encouraged me to trust my own judgment, which I have done.

I am grateful to Pastor Roland H. Swanson and Iola Tanquist, Program Coordinator, of Augustana Lutheran Church, Portland, Oregon, for the generous help and resources given in the conduct of this study.

A true debt of gratitude is due the individuals who actually were the substance of this study. They took the study seriously and were 
faithful in their commitment of time. I would like to list the names of all the people who served as subjects, but the rules of the Portland State University Human Subjects Committee require that I protect their anonymity.

I would like to thank the Institute on Aging for their interest in and support of my study, and for providing me with office space and a typewriter. Also, I would like to thank Mary Boucher, who has been particularly generous in her time in sharing her expertise and doing the final typing.

Finally, I dedicate this thesis to my family for their unfailing affection, support, and patience during my graduate study which made this research possible. I find so much pleasure in recognizing the very personal support of my husband, mentor, and best friend, Art, who has allowed me the courage to "be" in its fullest sense; my children, Stephen, Julie, and John, and granddaughter, Sarah Anne, who give me a reason for striving and achieving; and my parents, Aldevin and Ellen Laulainen, who first loved me and gave me a sense of moral integrity. 
TABLE OF CONTENTS

PAGE

ACKNOWLEDGEMENTS. . . . . . . . . . . . . . . . . . iii

LIST OF TABLES. . . . . . . . . . . . . . . . . . . vii

LIST OF FIGURES . . . . . . . . . . . . . . . . . . • . viii

CHAPTER

I INTRODUCTION: LITERATURE REVIEW AND DEFINITIONS. • . . 1

II METHOD. . . . . . . . . . . . . . . . 12

Subjects . . . . . . . . . . . . . 12

setting. . . . . . . . . . . . . 12

Procedure. . . . . . . . . . . . 13

Art Therapy Group. . . . . . . . . . . . 14

First Session ............ . 17

Second session. . . . . . . . . . 17

Third Session . . . . . . . . . 18

Discussion Group . . . . . . . . . . . 19

Measuring Instrument . . . . . . . . . 20

Independent Variable . . . . . . . . 20

Dependent Variable . . . . . . . . . 20

Controls................. 21

III RESULTS . . . . . . . . . . . . . . . . . 22

Statistical Results. . . . . . . . . . 22

Qualitative Results. . . . . . . . . . . 28 
CHAPTER

PAGE

Art Therapy Group: Session 1. . . . . . 28

Art Therapy Group: Session 2. . . . . . 40

Art Therapy Group: Session 3........ 46

Discussion Group . . . . . . . . 58

IV DISCUSSION AND CONCLUSIONS . . . . . . . . . . 62

BIBLIOGRAPHY . . . . . . . . . . . . . . . . . . 72

APPENDICES . . . . . . . . . . . . . . . . . . . 78 


\section{LIST OF TABLES}

\section{TABLES}

PAGE

I Summary Data for Art Therapy Group. . . . . . . . . 23

II Summary Data for Discussion Group . . . . . . . . . 24

III Summary Data for Control Group. . . . . . . . . . . . 25

IV Summary of Differences Between Pre- and Post-tests. . . 26

V Kruskal-Wallis ANOVA by Ranks . . . . . . . . . . . 27 


\section{LIST OF FIGURES}

1. Self-portrait: Subject 1, Age 78........... 31

2. Self-portrait: Subject 3, Age 75. . . . . . . - 32

3. Self-portrait: Subject 4, Age 72. . . . . . . . . 34

4. Self-portrait: Subject 5, Age 61........... 35

5. Self-portrait: subject 6, Age 65. . . . . . . . 37

6. Self-portrait: Subject 7, Age 62. . . . . . . . 38

7. Self-portrait: Subject 10, Age 61.......... 39

8. Significant Others: Subject 1, Age 78 . . . . . . 41

9. Significant Others: Subject 2, Age 73 . . . . . . 42

10. Significant Others: Subject 5, Age 61........ 44

11. Significant Others: Subject 9, Age 66 . . . . . . . 47

12. Significant Others: Subject 10, Age 61. . . . . . . 48

13. Mandala: Subject 1, Age 78. . . . . . . . . . 50

14. Mandala: Subject 2, Age 73............. 51

15. Mandala: Subject 3, Age 75. . . . . . . . . 53

16. Mandala: Subject 5, Age 61............. . 54

17. Mandala: Subject 6, Age 65............. 56

18. Mandala: Subject 8, Age 67. . . . . . . . . . 57 


\title{
CHAPTER I
}

\section{INTRODUCTION: LITERATURE REVIEW}

AND DEFINITIONS

\begin{abstract}
True, whoever looks into the mirror of the water will see first of all his own face. Whoever goes to himself risks a confrontation with himself. The mirror does not flatter, it faithfully shows whatever looks into it; namely, the face we never show to the world because we cover it with the persona, the mask of the actor. But the mirror lies behind the mask and shows the true face. (C. G. Jung. Archetypes of the collective unconscious, 1969.)
\end{abstract}

Despite a controversial history, projective techniques have been one of the major tools used by clinicians in their search for an accurate assessment of personality. These techniques are intended to reach the deeper and subtler levels of the unconscious in order to reveal specific conflicts, anxieties, complexes, and preoccupations that the individual may be unaware of.

Two of the more frequently used instruments are the Rorschach and the Thematic Apperception Test (Exner, 1976; Krech et al., 1974; Lindzey et al., 1975). Goodenough's (1926) Draw-a-Man was devised for estimating intellectual levels in children. Machover's (1949) Draw-a-Person provides clinical evaluation of personality and adjustment. Other examples of projective techniques are Make-a-Picture Story (Shneidman, 1949).

In recent years, increasing attention has been given to the projective modality, art therapy, as a valuable tool in diagnosis 
prognosis, and the actual therapy. Virshup (1978) believes any drawing or painting serves as a projective technique. She maintains "that all the marks we make on paper, all the colors and gestures we choose, are extensions of thoughts and feelings going on inside of ourselves" (p. 13). Virshup's method of therapy is to have people draw or paint and then describe what they "see" in their artwork. Her assumption is that whatever they "see" is in a very real sense a description of how they perceive themselves and their world.

Art therapy is a concept currently used to designate widely varying practices in education, rehabilitation, and psychotherapy (Ulman \& Dachinger, 1975) and can be defined as a non-verbal form of communication which provides the child or adult an opportunity to express feelings, thoughts, and emotions in an atmosphere that is presumed safe, accepting, encouraging, and fulfilling (Harms, 1975; Hodnett, 1973; Kramer, 1958; Naumburg, 1973; Quinn, 1978; Rhineberger, 1978; Shorr, 1974; Virshup, 1978; Vorbusch, 1977). Art therapy uses artwork as a non-verbal language which will allow a person to gain insight into his/ her own psychological makeup (Virshup, 1978) and allow the person to trust his/her own feelings. The creative experience allows for the loosening up of rigid defenses, fosters integration, and so provides the opportunity for the wholeness of the individual (Pine, 1975). Art therapy can be looked upon as an effective adaptive strategy for encouraging adjustment and growth, although it is not intended as a panacea for all adjustive problems.

Art therapy is a synthesis of art and psychology and as a form of psychotherapy, it has unique potentialities for personality support and enhancement (Hodnett, 1973). Powers and Langworthy (1978) support 
art therapy as an "integral part of a holistic treatment program" (p. 71). In their studies, artworks reflect changes a person makes in therapy; it is also a medium which promotes the individual's awareness of his/her own feelings and interactions with others so that he/she may choose whether or not to change. Shorr (1974) claims artwork helps a person focus for a change in his/her self-definition and when combined with dialogue, heightens awareness. He also states a person's imagery, more than any other mental function, indicates how he/she organizes his/her world.

A number of art therapists advocate the group art therapy modality over the individual because it involves several dynamic and interrelated aspects such as:

(1) Involvement - an interest in, or a sense of being "caught up in," and concerned with process.

(2) Identification with the group - entry into new activities often is accompanied by formation of new social interactions.

(3) Communication with the individual's surroundings artwork becomes a new form of expression.

(4) Catharsis - a release of emotional energy through the experience of creating.

(5) Greater life satisfaction - through the creative interaction, the individual's life becomes more meaningful, i.e., life is fuller, richer, more interesting.

(Durkee, 1964; Gendlin \& Olsen, 1970; May, 1978; Meyerhoff, 1977; Prađos, 1951; Rhyne, 1973; Rogers, 1961). 
Virshup (1978) believes that it is the process in art therapy that is important and not the product itself, and that this modality "allows us permission to be ourselves and yet relate better with others who may see things differently. It lets us deal with the conflicting desire to be an individual and yet part of the group" (p. 72).

In reviewing the literature and tracing the development of art therapy, it is evident that the role of this modality has grown in the helping professions within the past twenty years and has become a successful and acceptable technique. It is important to point out that art therapy can provide a place and method for experimentation with new ways of expression not only in the form of painting, drawing, and sculpture but also through all forms of the "arts" as well, i.e., poetry, dance, music, and drama.

In working with the mentally retarded and psychotics, art therapy has been reported by many therapists as a successful adjunctive technique in affording poor verbalizers an avenue of expression (Arnheim, 1977; Honig, 1977; Naumburg, 1950; Perkins et al., 1977; Powers \& Langworthy, 1978; Rogers, 1977; Steidel, 1979; Vaccaro, 1977; Vorbusch, 1977; Williams et al., 1977; Wilson, 1977).

Vorbusch (1977) finds that artwork for the schizophrenics holds no fear--color and form are not considered damning, only words. He also finds a greater tactile sensation exists between the patient and the environment during art therapy than during verbal modalities. Vorbusch feels this is an important factor and goes on to report that the art process, if the patient is appreciated as a potentially creative individual, can strengthen ego reintegration whether the creative process is active or passive. 
perkins et al. (1977) report that art therapy was invaluable during the year a young schizophrenic was dialyzed. It gave the patient faith in her inner vision and belief in its meaningfulness. The patient came to respect her images as symbols that could communicate to others. The patient's re-entry into reality was reflected in and measured through her artwork.

In an effort to assess the status of art therapy, Anderson and Landgarten (1974) surveyed the Midwest and Southern California. The results of their study confirm art therapy as a viable treatment method.

Art therapy is successful only if the therapist is knowledgeable in theory and skilled in its implementation. An art therapist is defined as a person engaged in the use of art directed toward the therapeutic changes in the patient or client (Anderson \& Landgarten, 1974). The art therapist sets the stage and Quinn (1978) thinks it advisable to give structure to an art therapy session without being authoritarian or threatening, whether with a single patient or with a group. His four basics for an effective art therapy session are;

(1) Set a time limit.

(2) Limit or expand the space to correlate comfortably with the number of patients in the group.

(3) Limit the project as to number of colors and/or as to the materials to be used. This will minimize distress and the confusion arising from choices:

(4) Be consistent, yet flexible.

Quinn also feels "a rigid structure is contraindicated when the patient feels safe enough to explore the infinite possibilities of 
forms, shapes, symbols, etc., that are available within the media used and from his/her own unconscious" (p. 79).

Arieti (1976) advocates that the therapist encourage spontaneity in order to promote a maximum range of possibilities immediately available to a person's psyche because of that person's intrinsic qualities and experiences, past and present. Perls (1969) and Rhyne (1973), both Gestalt therapists, speak of the necessity of spontaneous dialogues between the various opposing sides within us in order to express feelings which build up inside.

Rogers (1961) feels it is the responsibility of the therapist to provide psychological safety in a therapeutic group. To create this safety, some factors to consider are:

(1) Accept each person as a unique individual, of unconditioned worth.

(2) Provide a climate in which external evaluations are absent.

(3) Understand empathically--that is, the therapist should try to enter the private world of the individual and see it as it appears to that individual.

Rogers feels that if this climate is present, the authentic self of the individual can emerge and be expressed in varied and novel formings as the person relates to the world.

Thus, the success of any art therapy session depends a great deal on the expert ability of the therapist to permit creative freedom (Robbins, 1978). The therapist must be aware also that "permission to be free also means that one is responsible. The individual is as 
free to be afraid of a new venture as to be eager for it; free to bear the consequences of his/her mistakes as well as of his achievements" (Rogers, 196I, p. 359).

Wittels (1978) finds it important for the art therapist to apprecciate the message of the artwork and acknowledge it as worthwhile--the emphasis is more on the benefit to the person than on the creation of the artwork itself. In this approach the experimenter will actively participate in the art activities in an encouraging rather than judgmental fashion. Steidel (1979) worked with mentally retarded adults on similar principles. The experimenter ascribes to Patterson's (1974, as cited by Davis \& Klopfer, 1977) philosophy that therapists should be concerned about how to be somebody with their clients rather than seeking for something to do to their clients as many therapists are prone to do. Ulman (1975) feels "therapists, if they believe in the value of nonverbal communication, can deserve and gain respect when they relate to patients through the patient's artwork rather than through words" (p. 32).

In recent years the trend has been not only to extend psychotherapy to the aged population, but to explore and incorporate new modalities of therapy. One of the more effective modalities has been art therapy used not only as a diagnostic tool but as a dynamic therapeutic process. Arieti (1976) believes creativity can occur at any age, even the most advanced age, and can have a salutary effect on the older person.

Zeiger's (1976) work as an art therapist in the Hebrew Home for the aged in Washington, D. C. convinced her that art therapy, geared 
to Butler's (Butler, 1963; Butler \& Lewis, 1977) life review process, can be of significant value to the aged individual. She found it "normal for old people to talk about their past. The sensitive use of art activities can stimulate the recall of forgotten or repressed material and thereby further the personality reorganization of the life review process" (p. 50). Zeiger cautions that the life review is not a panacea for all the problems of the aged, but it can lead to a happier state of being.

Butler (Butler \& Lewis, 1977) advocates the life review process as being especially helpful to older people. He sees a review of one's life as occurring naturally and arising out of the aged person's need to reexamine and resolve past conflicts. This is necessary, in Butler's view, in order that the aged person can restructure his/her present experience in the face of impending death. In the psychotherapeutic setting, a formal life review process consists of obtaining an extensive biography of the person from the individual himself as well as from family and friends. The life review involves consideration of not only pleasurable memories, but painful memories--thus the advisability of the older person being in a setting where he/she may be assured of assistance in resolving conflicts and finding inner peace.

According to Butler and Lewis (1977), old age has unique developmental work to do. A major task is to clarify, deepen, and find use for what one has already attained in a lifetime of learning and adapting. Butler and Lewis feel it is imperative that older people, either in a social or therapeutic setting, continue to develop and change in order to enjoy a satisfying later life. 
Erikson (1963) states that the individual's ego progresses through a reliable sequence of stages in the development of personality from infancy to adulthood, and that the knowing "Who I am," and "Who I am to become" are crucial aspects of the integrative task of the elderly. He feels it is important for the individual to achieve and maintain a sense of the uniqueness and importance of one's life for what it has been in the past and is at the present. According to Erikson, a crisis will occur if the aged person cannot look back on his/her life as having been worthwhile and accept both the good and the bad, based on his/her own moral code.

Other theorists and practitioners have also developed concepts to explain the healthy personality in old age which include a review of one's life and search for identity: Jung's (1953) concept of individuation in view of one's death; Fromm's (1941) notion of activity and maintaining some measure of productivity in later life; Henry and Cumming's (1959) view of role readaptation or relinquishment; and Neugarten, Havighurst, and Tobin's (1961) measure of life satisfaction. Manaster (1972), in group therapy with "senile" geriatric patients, found that more than anything else the prime need was a sense of identity. Jones (1977) sees aging as ongoing and natural and, in order to allow for further growth in later life, feels conflicts which dominated the individual at earlier stages must be resolved. She further states that successfully aging persons have a sense of acceptance of age and the future which is death, acceptance of past and present iife, and satisfying emotional relationships with others.

The study here reported has investigated the effectiveness of the use of art therapy with people in later life as a mechanism for 
increasing the quality of an informal life review and for motivating them toward greater psychological well-being (life satisfaction). This study was inspired in part by zeiger's (1976) art therapy program with the aged in which she incorporated a life review with the art sessions. To overcome some obvious shortcomings of Zeiger's study which only had one group, two additional groups were incorporated in the present research. Unlike previous art therapy studies, a measure of life satisfaction was done before and after the study to find out if the component of art therapy contributes to a greater life satisfaction. The dependent variable, life satisfaction, was measured by the Life satisfaction Index-A (ISIA) (see Appendix A) developed by Neugarten, Havighurst, and Tobin (1961) (Adams, 1971; Wood, Wylie, \& Shaefor, 1969) who found a strong positive relationship between social activity and life satisfaction. Because of this, art therapy in this study was implemented in a social context.

Thirty subjects were recruited on a voluntary basis from Augustana Iutheran Church, Portland, Oregon, and the surrounding neighborhood. The church is located in a middle-class neighborhood. Twenty-three of the subjects chosen are of the Lutheran faith; the remaining seven subjects are of various other religious faiths.

Following the pre-test, the subjects were assigned to one of three experimental groups based on their availability and time commitment: (1) Art Therapy Group, (2) Discussion Group, or (3) Control Group. The amount of time spent in therapist-group contact was the same for both the Art Therapy Group and Discussion Group. The Control Group did not participate in any group process; all subjects took the pre- and post-tests. 
It was hypothesized that there would be differences among the three groups in life satisfaction scores as determined by appropriate statistical measures. It was predicted art therapy would produce greater life satisfaction. 
CHAPTER II

METHOD

\section{Subjects}

Thirty subjects were recruited on a voluntary basis from Augustana Lutheran Church, Portland, Oregon, and the surrounding neighborhood. The experimenter solicited subjects through advertising in the church bulletin, attending the Senior Adults meeting, and personally asking people to participate.

The criteria for selecting subjects were reasonably good health, ambulatory, age over 60 , and an interest in participating in art/ discussion group activities. Willingness to participate was indicated by signing the consent form (see Appendix B). Obtaining this signed consent form turned out to be a serious problem (see Appendix D).

All subjects were informed of the general nature of the study but were not told of the specific hypothesis. After the study, the subjects in the Art Therapy Group and Discussion Group were debriefed as a group in their respective groups. The Control Group subjects were individually debriefed.

\section{Setting}

The study took place at Augustana Lutheran Church, Portland, Oregon, in a suitable private room with reasonably comfortable chairs and tables, proper lighting, and comfortable room temperature. Appropriate and private storage for the artwork and supplies was 
provided by the church. The author is grateful to Pastor Roland Swanson and Iola Tanquist, Secretary/Program Coordinator, of Augustana Lutheran Church, Portland, Oregon, for the generous help and resources given in the conduct of this study.

\section{Procedure}

The experimenter contacted the Pastor of Augustana Lutheran Church requesting permission to conduct the study on the premises and to solicit volunteers.

The subjects were informed this was a study exploring life satisfaction in later life and that the participants would take several tests and should be willing to participate in an art-related activities group or a discussion group. The time commitment for the Art Therapy Group and Discussion Group was three weeks each with a ninety-minute session per week.

Following the Life Satisfaction Index-A pre-test, given individually at time of recruitment, the subjects were assigned to one of three groups: (1) Art Therapy Group, (2) Discussion Group, or (3) Control Group. Pure randomization was not feasible due to the subject's availability on the two days set by the experimenter as experimental times. The experimenter arbitrarily set Tuesdays (April 1, 8, and 15, 1980) as the days for the Art Therapy Group and Thursdays (April 3, 10, and 17, 1980) as the meeting times for the Discussion Group. The people who had expressed an interest in participation in the study were called by the experimenter who asked if they were available on Tuesdays or Thursdays. Based on their answers, they were assigned to one of the three groups. The subjects in the Art Therapy Group and Discussion Group were 
not aware of which group they were assigned until they arrived at the first session and were presented with the instructions. The Control Group consisted of interested subjects who were not available Tuesdays or Thursdays at the given times and were informed of their assignment individually. No systematic difference between those who had Tuesdays or Thursdays free is known to the experimenter, so this procedure approximates a true random assignment as closely as possible in the circumstances.

Both the Art Therapy Group and the Discussion Group began and ended promptly at the stated times, i.e., 10:00-11:30 a.m.

Once admitted to one of the two experimental groups, Art Therapy or Discussion, the subjects were asked to adhere to regular attendance in order to maintain continuity of the group process and progress. The Control Group members were advised only of the pre- and post-tests.

The focus of the two experimental groups, Art Therapy and Discussion, will be discussed separately.

\section{Art Therapy Group}

This group met once a week for ninety minutes over a three-week period. The group consisted of ten subjects, only three of whom had done any kind of art activities prior to the study. Many of the subjects initially displayed a reluctance to participate since they had never drawn before. It was stressed by the experimenter throughout all three sessions that artistic ability was not necessary, that all drawings were to be considered worthy of praise and as a form of very personal expression, regardless of their artistic merits (Vorbusch, 1977) 
The experimenter participated in the art activities along with the subjects, thus demonstrating the focus of the activity and promoting an atmosphere of encouragement. At the same time, the experimenter reassured the subjects by revealing her own artistic strengths and limitations (Rogers, 1961).

To get at the roots of the subject's life experiences, the art projects were designed to operate on an emotional or subjective level, thereby releasing memories bound up in the unconscious (May, 1978; Rogers, 1961).

After each art exercise, the group discussed the pictures. The members were encouraged to describe verbally what he/she had experienced visually. The experimenter initiated the discussion by sharing her own artwork and disclosing personal thoughts about the creation, a method similar to the technique of "self-disclosure" (Jourard, 1971). This served as the format for the group and the subjects freely entered into the process of interpreting their creations. The group interaction appeared to provide non-verbal role modeling, with the more creative and adventurous individuals helping the less assertive people try out new behaviors such as sharing new insights (Virshup, 1978; McNiff, 1973).

The group interaction not only stimulated older memories but also encouraged immediate interaction (Dewdney, 1975). Rogers (1961) supports the therapeutic value of group sharing of artwork:

It is doubtful whether a human being can create without wishing to share his creation. It is the only way he can assuage the anxiety of separateness and assure himself that he belongs to the group . . . he desires to communicate with a group which will understand him . . . He does not create in order to communicate, but once having created, 
he desires to share this new aspect of himself-in-relationto-his environment with others (p. 356).

While sharing a creation and sharing the deep meaning of that creation are not the same, the experimenter believes that in the group process of interpreting one's artwork deep personal meaning may also be revealed. Dewdney (1975) also gives credence to the group sharing facet of art therapy by stating that it is:

as important as the artwork itself for the following two reasons: First, attention and concern of the total group is focused on the drawing of each person, thus giving it importance it might not otherwise have. Second, the subject's critical faculties are stimulated by their having to articulate spoken judgments (p. 130).

The first two assignments require the use of memory; the third assignment requires imagination and allows fantasizing.

At the end of each session, the subjects were encouraged to sign and date the back of their artwork (only first names were used to assure partial anonymity outside the group itself). Dewdney (1975) found this an important aspect of identity and self-esteem.

The experimenter made no interpretations or judgments but rather encouraged the members to interpret their own artwork. Virshup (1978) stresses that it is "unnecessary for anyone to assume the role of interpreter, and tell the artists what their drawings mean. Such interpretations tend to close off the communication process; it can leave the artists who have become vulnerable by self-disclosure feeling invaded by an authority telling them what, how, and who they really are" (pp. 19-20). Interpretations by therapists often tend to destroy the comfortable and safe environment necessary for openness, insight, and growth. 
First Session. The assignment was to draw a self-portrait on a $22.86 \mathrm{~cm} \times 30.48 \mathrm{~cm}$ sheet of white drawing paper using Oil Pastels and/or felt tip pens. The goal of this exercise was self-concept--how the person sees the self. Factors observed by the experimenter and group members were the mood indication of the portrait. Kivalo (1978) states that the person's own body image is an essential background factor of his/her identity. By body image, he means "how we experience our own body, its quality, size, and sensations" (p. 94). Kivalo feels that some features of the body image remain constant even with growing old, such as drawing a self-portrait younger than it is in reality.

Kivalo also states that the size of the drawing indicates the degree of the person's self-esteem. Figures of very small size may reveal inferiority or depression, but the assessment of this factor must be approached with caution. Occasionally poor self-esteem, in Kivalo's experience, is negated and compensation is achieved by drawing an expansive figure. According to Vorbusch (1977), ego reintegration is facilitated through a person having his/her portrait painted.

Second Session. The assignment of this session was to draw a picture of significant others at any point in time. The subjects were instructed to use stick figures and put themselves in the picture. The drawings were done on $22.86 \mathrm{~cm} \times 30.48 \mathrm{~cm}$ white drawing paper using Oil Pastels and/or felt tip pens.

The focus of this activity was. how the person perceives his/her social world (Butler \& Lewis, 1977). Factors observed by the experimenter and group members were location of the subject in relation 
to the other people, size of the subject in comparison to the others, how many people in the group, who the people are, whether or not the subject has happy associations with the picture, what memories are associated with the drawing, and how the person views self in the company of others.

If a person draws himself/herself small and/or off to one side, according to some practitioners (Butler \& Lewis, 1977; Kivalo, 1978; Vorbusch, 1977), the person could feel diminished, helpless, a loss of autonomy, despair, et cetera.

Third Session. The final art form, the mandala, was chosen to trigger the unconscious memories. The drawing was done on $22.86 \mathrm{~cm} \mathrm{x}$ $30.48 \mathrm{~cm}$ white drawing paper using Oil Pastels and/or felt tip pens. The subjects were asked to outline a circle by drawing with a pencil around a paper plate. They were given the following instructions (MacRae, 1977):

We use the circle, which is called a mandala because it is a symbol of order--order in the universe and the inner order of the self. I want you to try to center and balance within the circle because it will help to center and balance you. Think of things in nature that open from the center, like flowers and snowflakes and seashells. You are part of nature and you have a center which you want to keep open and flowing. Start in the center--your center--with a shape and a color and let your design flow from there. Sometimes you can learn something about yourself, so we will talk about your mandala when you have finished it (p. 130).

The subjects were encouraged to use colors to fill in the circle in his/her own way (Bonny et al., 1977; Kellogg et al., 1977; Musick, 1976). Free choice of color ( 24 colors were available) was encouraged but no attempt was made to interpret the significance of colors used. Each subject was encouraged to express his/her own fantasies. 
"The mandala is a universal symbol; a complex visual pattern that symbolizes the nature of the mind or reality" (Krech et al., 1974). According to Jung (1977), the mandala is a universal symbolic representation of self and/or one's perception of his/her world. People with minimal life satisfaction can block out experiences which should and can be resolved. The execution of the mandala is a way of opening up new options and possibilities, and facilitates finding new ways of organizing one's environment in order to penetrate beneath the surface. Jung, in his later years, came to emphasize the spiritual side of man's existence. He discovered individuals in later life for whom life had lost its purpose. Jung felt that the person, in order to achieve full individuation, must form a psychological organization that can reconcile all of the opposing and contradictory trends within the psyche. His method of helping his patients attain individuation involved the process of active imagination. Jung instructed his patients in the art of consciously focusing on dream images or on fantasy figures in an effort to elaborate them and to embellish such unconscious creations in a very purposeful and therapeutic manner. Active imagination enables the individual to capitalize on his/her own self-knowledge that would otherwise remain untapped. In this way, the individual can examine many aspects of his/her personality (Jung, 1953). At the end of the third Art Therapy session, the post-Life Satisfaction Index-A test was given to the group as a whole.

\section{Discussion Group}

This group met once a week for ninety minutes over a three-week period. The topics for discussion were left up to the group to decide, 
but the experimenter suggested topics and encouraged an informal life review. The experimenter assumed a monitoring role to insure all members had a chance to participate during each session.

At the end of the third session, the post-Life Satisfaction Index-A was administered to the group as a whole.

\section{Measuring Instrument}

Two measures were made on each subject: One measure prior to the experiment and a second measure after the study, using the Iife Satisfaction Index-A (LSIA). LSIA was developed by Neugarten, Havighurst, and Tobin (1961) and has defined well-being as a strictly internal construct, independent of the exterior conditions of a person's life. Neugarten et al. identified and operationally defined five components of psychological well-being and called them life satisfaction. These components are: Zest for life as opposed to apathy; resolution and fortitude as opposed to resignation; congruence between desired and achieved goals; high physical, psychological, and social self-concept; and a happy, optimistic mood tone (Alexander, 1979).

\section{Independent Variable}

The independent variable is treatment and there are two treatment conditions, art therapy and discussion.

\section{Dependent Variable}

The dependent variable is the measure of life satisfaction (on the ISIA) of the subjects before and after the treatment. 


\section{Controls}

The following steps were taken to minimize error variance:

(1) The subjects' nervousness or anxiety in participating in a study and/or in a group was controlled by serving coffee at all sessions. The subjects were encouraged to arrive ten to fifteen minutes early so that they could interact socially before the sessions began.

(2) Outside envirommental distractions were minimized by obtaining a private room for test administration and group sessions. Visitors were not allowed in the room during the experiment.

(3) The experimenter maintained uniformity in instructions throughout the experiment. The subjects were given sufficient time to do the pre- and post-tests.

(4) In the absence of true random assignment to the groups, error variance due to individual differences was minimized by checking group homogeneity by analyzing the pre-test using the nonparametric Kruskal-Wallis ANOVA by ranks which showed that the three groups were similar at the outset.

(5) Data analysis error was minimized by careful measurement, calculation, and checking of results. 


\section{CHAPTER III}

\section{RESULTS}

The results of this study will be presented in two parts: statistical results and qualitative results.

\section{Statistical Results}

In the absence of true random assignment to the groups, error variance due to individual differences was minimized by checking group homogeneity by analyzing the pre-test using the nonparametric KruskalWallis ANOVA by ranks which showed that the three groups were similar at the outset. Corrected for ties, $\underline{\mathrm{H}}=0.40,\left[\chi^{2}(2)=5.991, \underline{\mathrm{p}}>.05\right]$.

The means and standard deviations for the three experimental groups are summarized in Tables I through IV.

Using the differences between the pre- and post-tests as the dependent variable, the nonparametric Kruskal-Wallis ANOVA by ranks showed no significant difference between the three groups in measure of life satisfaction. Corrected for ties, $\underline{H}=4.27,\left[\chi^{2}(2)=5.991\right.$, $\underline{p}>.05]$. These data are summarized in Table $v$. The data failed to support the prediction that art therapy would produce greater life satisfaction than either the Discussion Group or the Control Group. The author also did the ANOVA two-factor mixed design: Repeated measures on one factor which confirms this result (see Appendix C).

To test for differences between the groups, a nonparametric MannWhitney U-test was used. Comparison between the Art Therapy Group and 
TABLE I

SUMMARY DATA FOR ART THERAPY GROUP

(BASED ON SCORES ON THE LIFE

SATISFACTION INDEX-A*)

$$
\mathrm{n}=10
$$

\begin{tabular}{|c|c|c|c|c|}
\hline Subject & & Pre-test & Post-test & Difference \\
\hline Subject & 1 (Age 78) & 10 & 12 & +2 \\
\hline subject & 2 (Age 73) & 16 & 15 & -1 \\
\hline Subject & 3 (Age 75) & 16 & 16 & 0 \\
\hline subject & 4 (Age 72) & 16 & 18 & +2 \\
\hline Subject & 5 (Age 6l) & 6 & 8 & +2 \\
\hline Subject & 6 (Age 65) & 15 & 13 & -2 \\
\hline Subject & 7 (Age 62) & 17 & 18 & +1 \\
\hline Subject & 8 (Age 67) & 18 & 18 & 0 \\
\hline Subject & 9 (Age 66) & 10 & 13 & +3 \\
\hline Subject & 10 (Age 6l) & 14 & 16 & \pm 2 \\
\hline & Total & 138 & 147 & +9 \\
\hline & Mean & 13.8 & 14.7 & \\
\hline & Standard Deviation & 3.853 & 3.233 & \\
\hline & Variance & 14.845 & 10.452 & \\
\hline
\end{tabular}

Age range: $61-78$

Mean age: 68

Range of scores: Pre: $6-18$

Post: $8-18$

*Total possible score on the Life Satisfaction Index-A $=20$ 
TABLE II

SUMMARY DATA FOR DISCUSSION GROUP

(BASED ON SCORES ON THE LIFE

SATISFACTION INDEX-A*)

$$
\mathrm{n}=10
$$

\begin{tabular}{lccc}
\hline Subject & Pre-test & Post-test & Differences \\
\hline Subject 11 (Age 72) & 16 & 18 & +2 \\
Subject 12 (Age 69) & 11 & 11 & 0 \\
Subject 13 (Age 65) & 11 & 12 & +1 \\
Subject 14 (Age 71) & 12 & 16 & +4 \\
Subject 15 (Age 70) & 15 & 20 & +5 \\
Subject 16 (Age 68) & 13 & 11 & -2 \\
Subject 17 (Age 61) & 15 & 16 & +1 \\
Subject 18 (Age 79) & 16 & 13 & -3 \\
Subject 19 (Age 61) & 16 & 16 & 0 \\
Subject 20 (Age 62) & 10 & 10 & 0 \\
Total & 135 & 143 & +8 \\
Mean . & 13.5 & 14.3 & \\
Standard Deviation & 2.369 & 3.368 & \\
Variance & 5.61 & 11.34 & \\
\hline
\end{tabular}

Age range: $61-79$

Mean age: 67.8

Range of scores: Pre: $10-16$

Post: $10-20$

*Total possible score on the Life Satisfaction Index-A $=20$ 
TABLE III

SUMMARY DATA FOR CONTROL GROUP

(BASED ON SCORES ON THE LIFE

SATISFACTION INDEX-A*)

$$
\mathrm{n}=10
$$

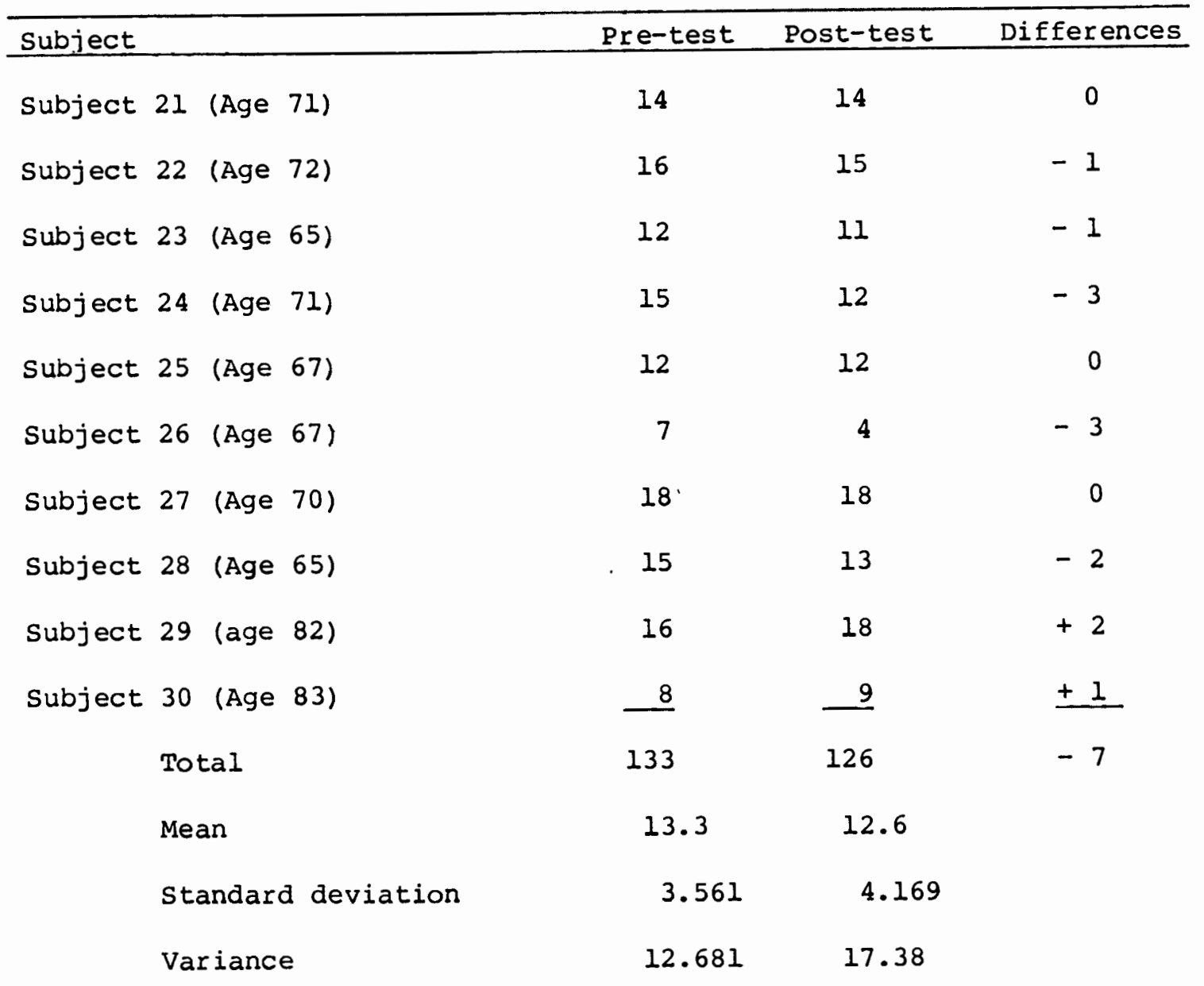

Age range: $65-83$

Mean age: 71.3

Range of scores: Pre: $7-18$

Post: $4-18$

*Total possible score on the Life Satisfaction Index-A $=20$ 
TABLE IV

SUMMARY OF DIFFERENCES BETWEEN PRE- AND POST-TESTS

(BASED ON SCORES ON THE LIFE

SATISFACTION INDEX-A*)

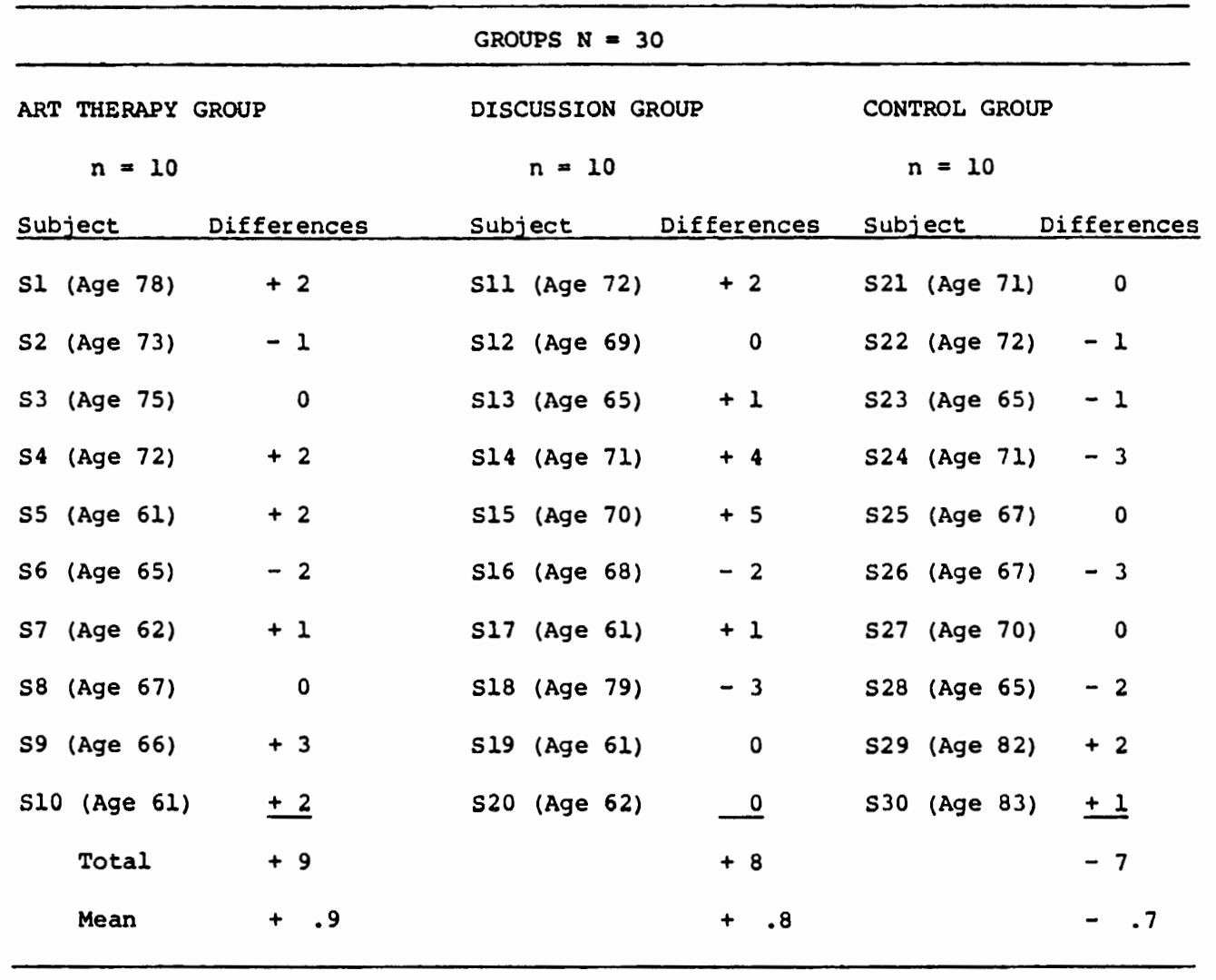

Overall age range: $61-83$

Overall mean age: 69.03

* Total possible score on the Life Satisfaction Index-A $=20$ 
TABLE V

KRUSKAL-WALLIS ANOVA BY RANKS: DIFFERENCES

BETWEEN PRE- AND POST-TESTS (BASED ON

SCORES ON THE LIFE SATISFACTION

INDEX-A*)

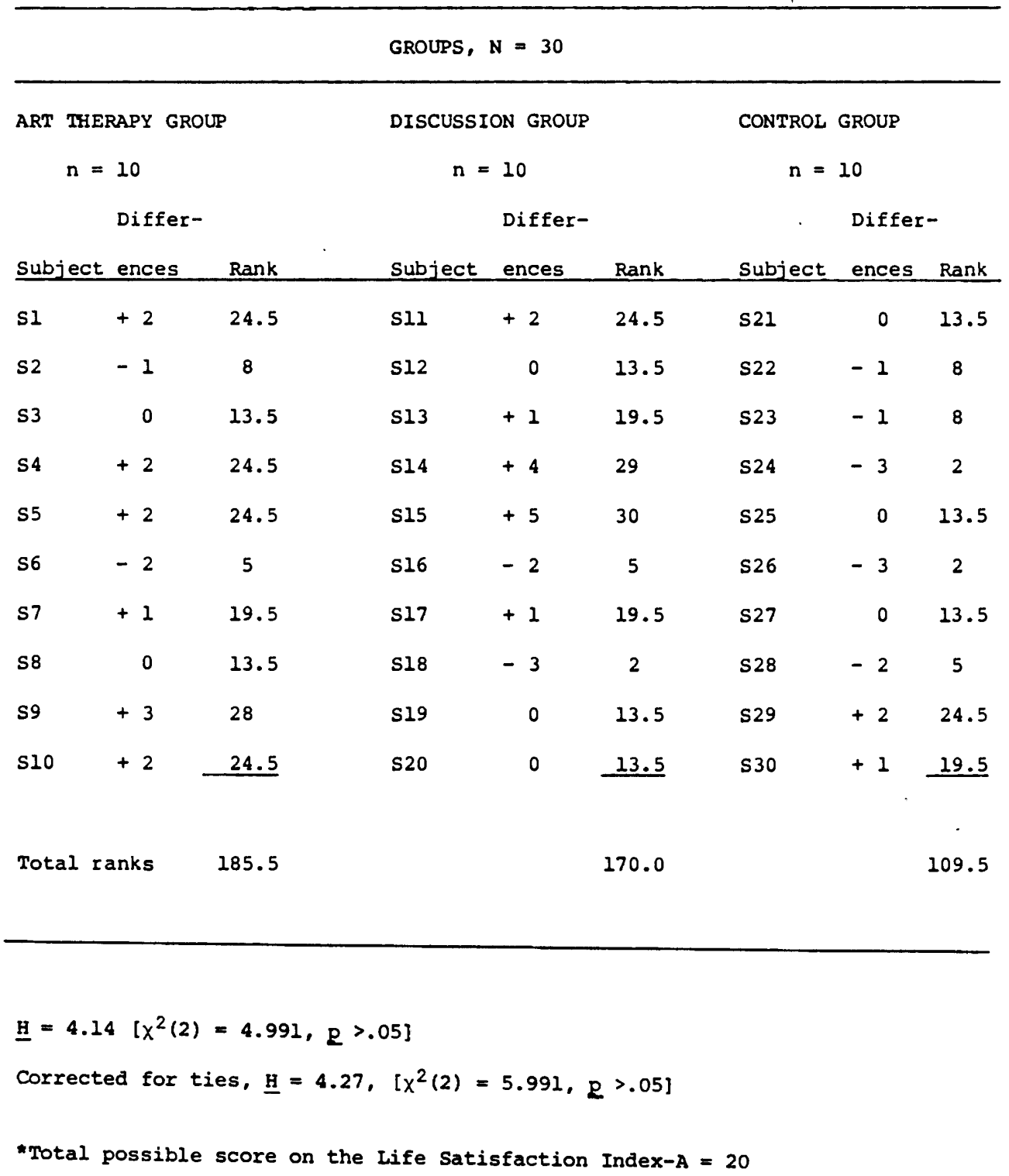


the Control Group was not significant when using a two-tailed test, $\underline{\mathrm{U}}=24,(\mathrm{R}: \underline{\mathrm{U}} \leq 23, \mathrm{Q}>.05)$; however, when using a one-tailed test, the

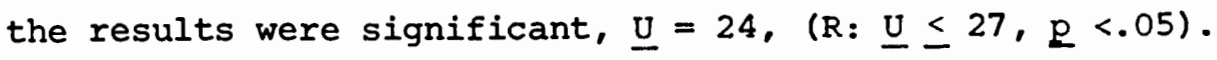

Comparison between the Discussion Group and the Control Group was not significant, $\underline{U}=30.5,(R: \underline{U} \leq 23, \underline{P}>.05)$, although the trend is in the right direction.

Comparison between the Art Therapy Group and Discussion Group was clearly nonsignificant, $\underline{U}=45.4,(R: \underline{U} \leq 23, \underline{p}>.05)$.

\section{Qualitative Results}

The two experimental groups, Art Therapy and Discussion Group, will be presented separately.

Art Therapy Group: Session 1. Initially, many subjects expressed shock when they realized they were in the art-activities group. Most of the group members had not drawn or painted since elementary school-several members said they had never drawn or painted prior to participating in this study, and claimed they were unable to draw a straight line. The role of the experimenter in this situation, as the participant-observer, was to encourage and allow the subjects to attempt for them the impossible. No pressure was used. The subjects were cooperative and took the study seriously. As the first session progressed, there was much laughter at themselves as well as with each other. The laughter is important because it served as a liberating factor, as well as bonding the group into a common endeavor.

The results were surprising to the subjects and many of the selfportraits revealed subtle nuances of the individual's personality. It was the consensus of the group that this was a new experience for them 
and that they had never allowed themselves to think about themselves in such a probing and personal way. The members had always focused on service to their families, friends, community, and church and rarely indulged in introspection.

When asked at the end of the first session how they felt about doing this project, the subjects all agreed that it was interesting, fun, and stimulating. They pointed out, however, that the trust in the group was very important. If they had not felt trust, they would not have been able to participate in such personal self-disclosure. One person commented that if anyone would have laughed at her or criticized or judged her works, she would not have returned regardless of the importance and worth of the study.

One member stated that perhaps one reason many older people do not take up painting or drawing is that when they were young, art was not encouraged--that abilities in later life depend on how talents were encouraged or discouraged throughout life. Another member said she lacked self-confidence, but because this was a study, she would be willing to go along with whatever was required.

It was interesting to note that the three subjects who had some previous drawing and/or painting experience exhibited the most frustration. All three shared the reason for their frustration: because the group knew they could do artwork, they felt a certain expectation of perfection. One of these subjects said she had tried to make her selfportrait "perfect" but laughed when she said that it was impossible. Another interesting group dynamic in response to this exhibited and shared frustration was that the group responded by comparing their own 
works with the so-called "artists." This only happened in the first session. The experimenter continually stressed that artistic ability was not necessary, that all drawings were considered worthy of praise and were a form of personal expression.

The following are a few examples of the self-portrait assignment: The oldest subject, age 78 (Figure 1) found it very difficult to talk about her self-portrait. She stated that the inner self was quite private and somewhat unknown even to herself--she preferred to talk about someone else. She laughed at her "humble" attempt and exclaimed, "Look at that big mouth! I just couldn't get it right." The group members responded by commenting that they did not see it that way. They saw her representation of a large mouth as depicting her warm and gracious interest in others. The group also pointed out that the big smile was a feature of a happy, generous, and loving woman. The subject appeared pleased by this feedback.

Subject 3, Age 75 (Figure 2), initially did not want to share her portrait. She said, "When you look at it, you'll see why. I tried to show my gray thin hair and I think I succeeded on that point. I think about getting a wig, but never quite get around to it. At least I put my glasses in the picture." with sort of a disgusted laugh, she added, "I've never thought of myself as attractive and this portrait really shows that! If this weren't such an important study, I wouldn't stay." She did state she liked the sharing of the group, that she just didn't feel she had anything to share that was worthwhile. It is important to note here that this woman's husband died six weeks prior to the start of this study. The group responded to subject 3 by telling her she was too hard on herself, that she had captured her expressive eyes and 


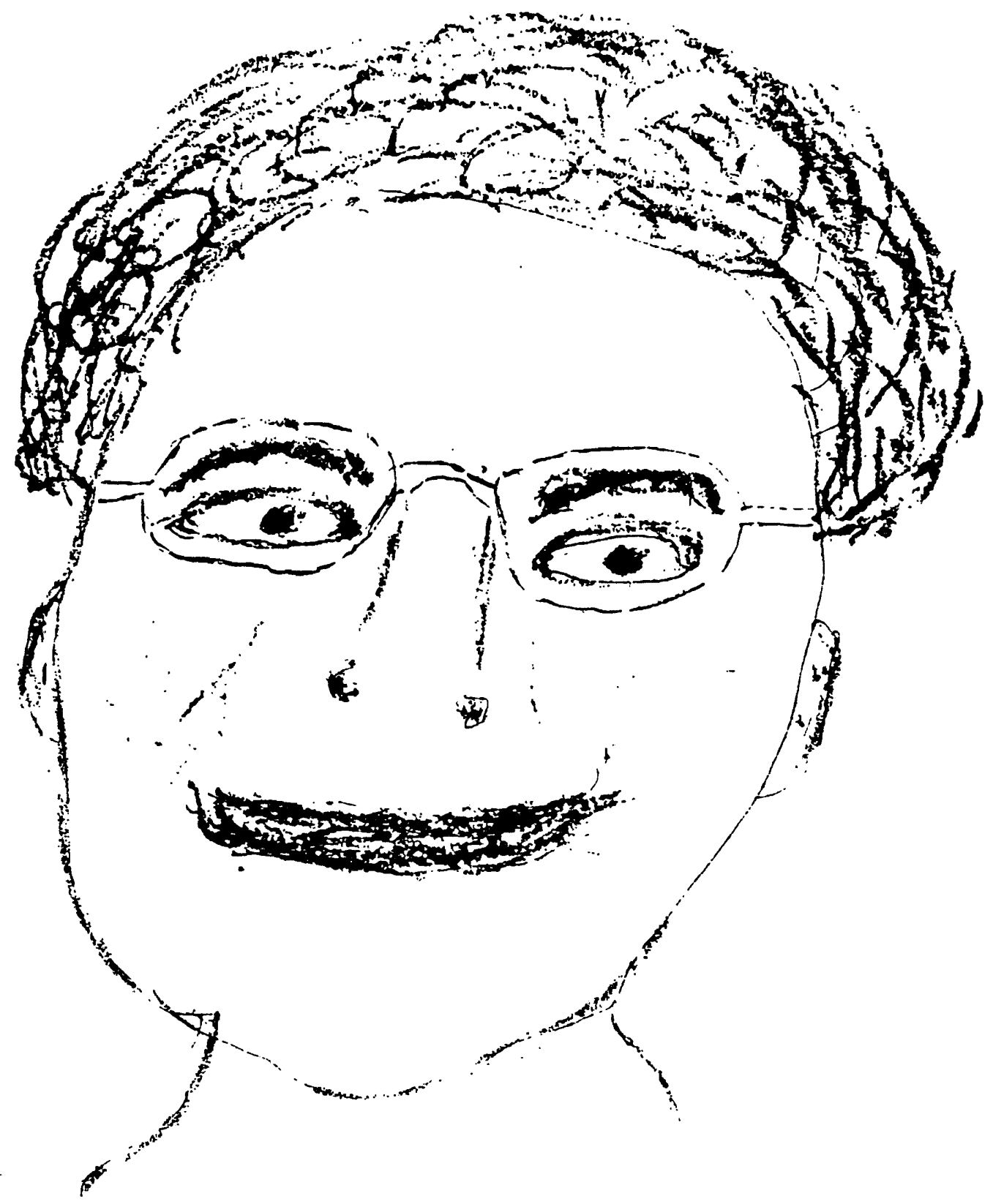

Figure 1. Self-portrait: Subject 1, Age 78. 


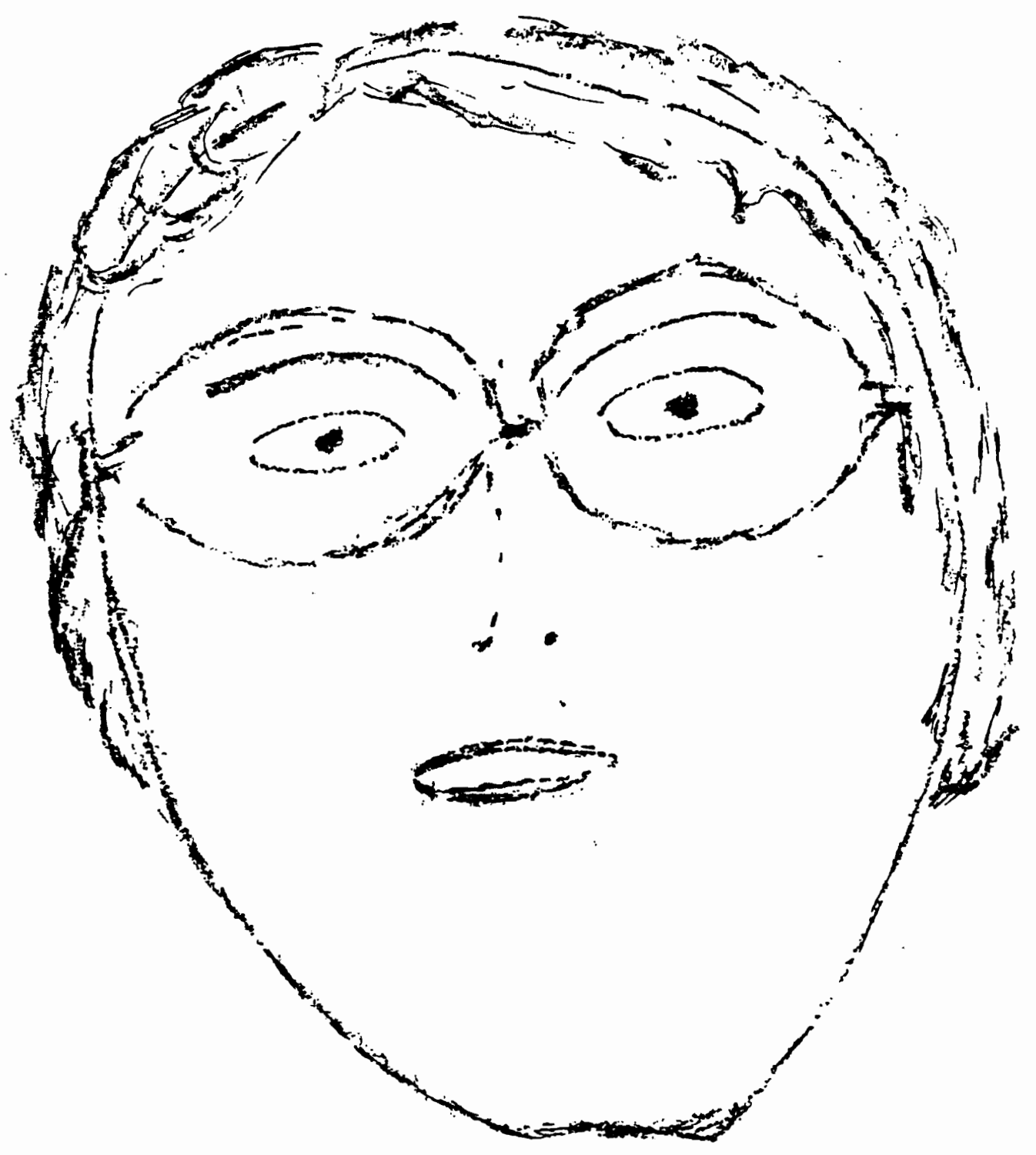

Figure 2. Self-portrait: Subject 3, Age 75 . 
friendly smile.

Subject 4, age 72 (Figure 3), said she did not realize how horrible she looked until she finished her portrait. She was unaware of drawing the wrinkles, or age lines (laughter), but felt that perhaps that's the way she looked. She produced a profile that uncannily captured her likeness. The group responded to subject 4 that she was too hard on herself and that she did not really have the wrinkles shown in the self-portrait. There was lots of shared laughter and a discussion about how we perceive ourselves differently than we actually are. In Figure 4, Subject 5, age 61, tried to capture her new more flattering hairdo but reflected that somehow it didn't quite look like her. The group agreed that the portrait did not look like her but that she had not included her glasses. They asked that she remove her glasses in order that they could then make a better comparison. Subject 5 hesitated for moment and then said, "Oh, well, what does it matter." When she removed her glasses, it became clear why she was reluctant. The glasses incorporated a hearing aid and she was very sensitive to this device and only recently had been able to accept the fact she had a hearing loss. For years she had withdrawn from many social activities because of her hearing impairment and suffered a great deal of embarrassment. She expressed a great relief to be able to express her sensitivity not only to another person but to a group. She was reassured that the group did not think less of her, but rather they shared some of their own worries of physical changes, losses, and limitations with age. She responded with a smile and said she had gained a new insight into herself and her lack of faith in her friends and acquaintances. She felt that compared to some of the "real" problems of others, perhaps 


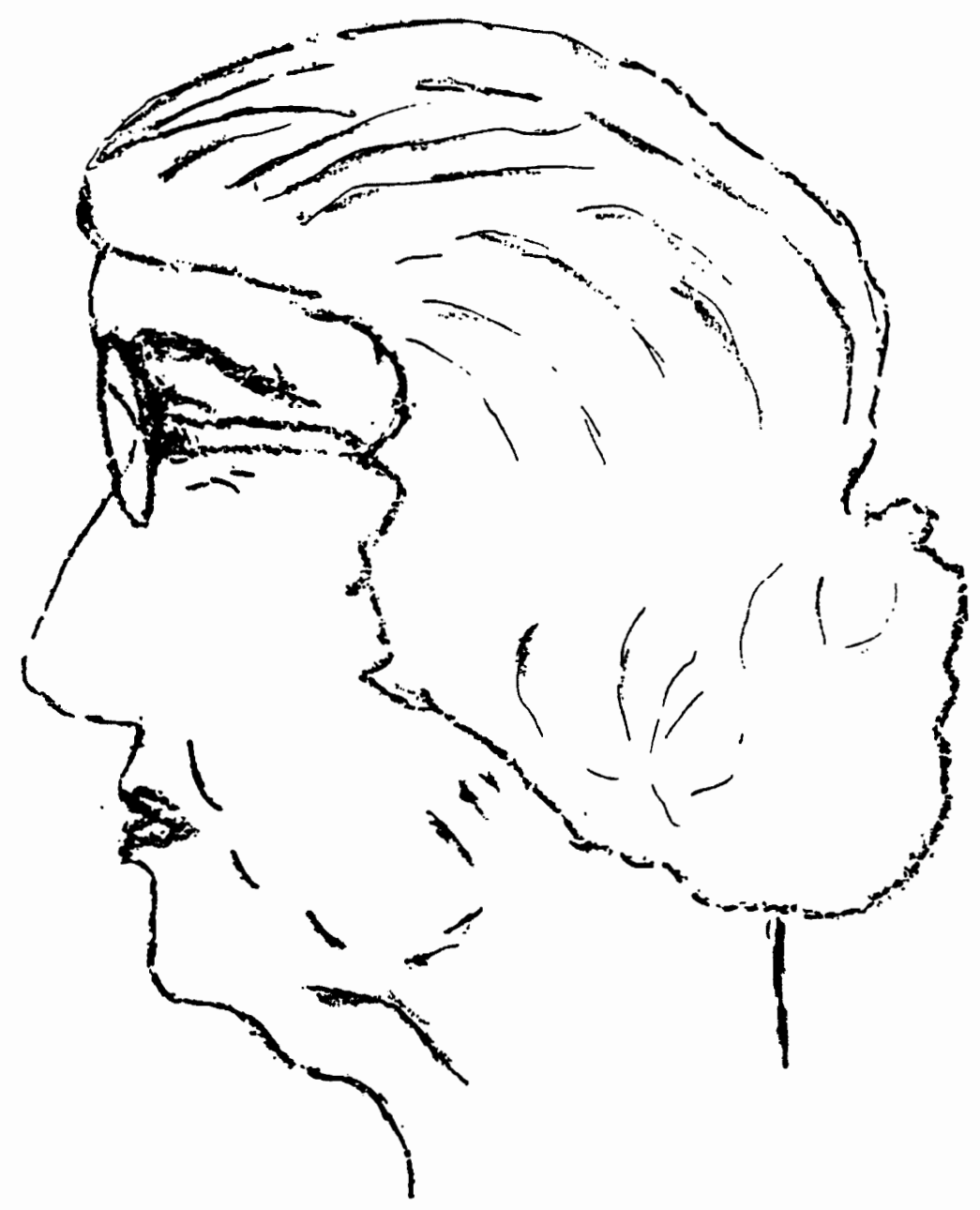

Figure 3. Self-portrait: Subject 4, Age 72. 


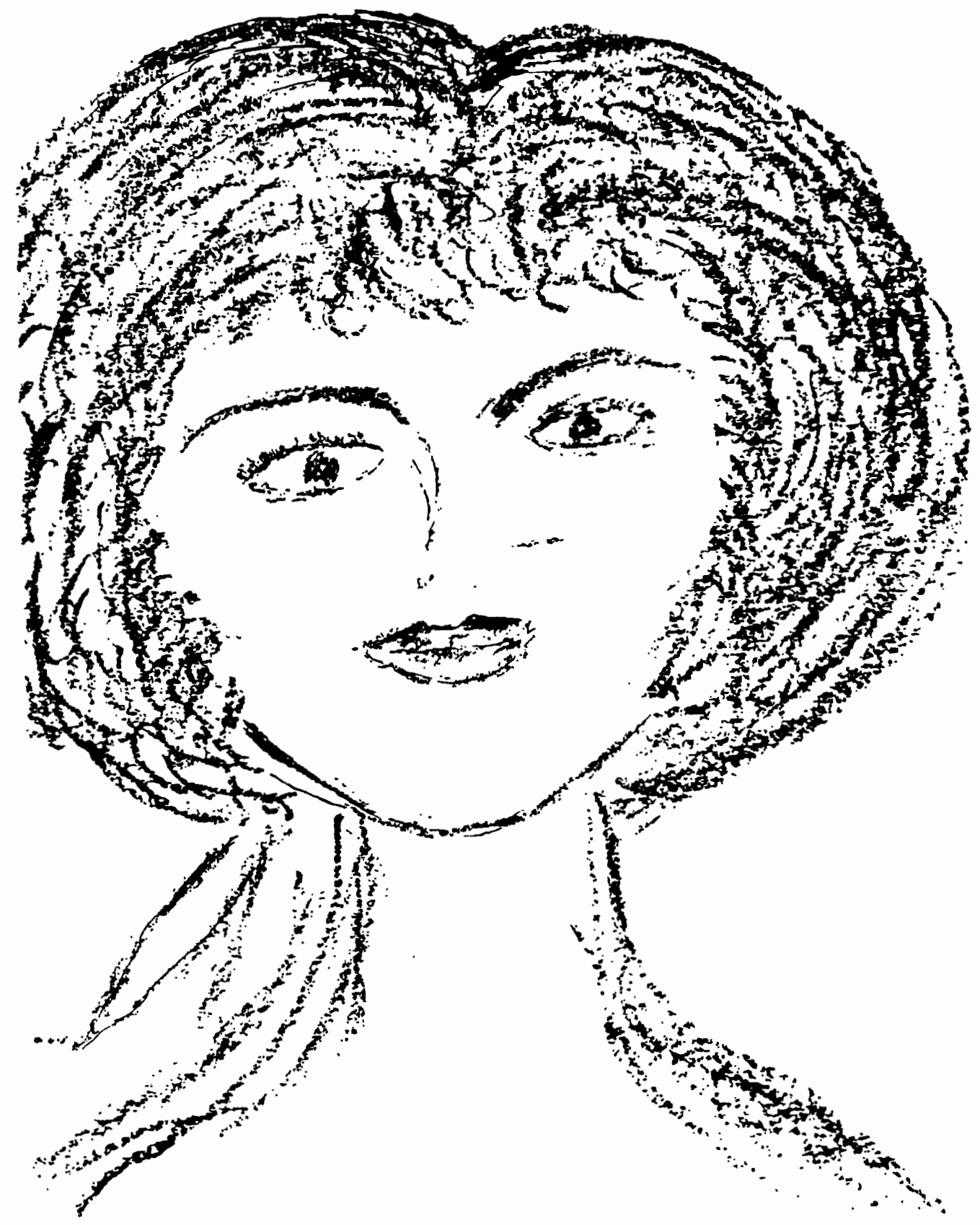

Figure 4. Self-portrait: Subject 5, Age 61 . 
hers was silly.

Subject 6, age 65 (Figure 5) depicts a woman who also was unable to capture her essence according to her judgment. She said laughingly, "This certainly does not look like me--the mouth particularly doesn't look like my mouth. So, what do we do about it? Just go on to something else, I guess (laughter)." She also said she had gotten so engrossed trying to get all the curls on her head that she ran out of paper and had to tape on an extension. She philosophically pointed out that how we look at ourselves changes from day to day--there are days when a person does not feel good even to the self and she wondered if the self-portraits would reflect this change. The group responded to Subject 6 by finding a great deal of likeness in her portrait. They saw the large mouth as depicting her openness, friendliness, and willingness to help other--the same response was given subject 1 .

Subject 7, age 62 (Figure 6), an artist of recent years, captured her likeness at a younger age. The group responded that it was an exact likeness. The author wonders if the group responded in this manner with an obvious distortion of reality because the woman presented herself as an artist. Subject 7 described her portrait as pensive and wondered what whe was thinking about so seriously. In examining the exaggerated eyebrows, she recalled her sister cut her eyelashes when she was a toddler. She then laughed and expressed a gratefulness that her sister had not poked her eyes out. She shared that she had not thought of this incident for a long time and that the memory was triggered only upon examining and talking about the self-portrait.

Figure 7, Subject 10, age 61, also depicts one of the artists in the group. Because she was an artist, she felt a certain expectation 


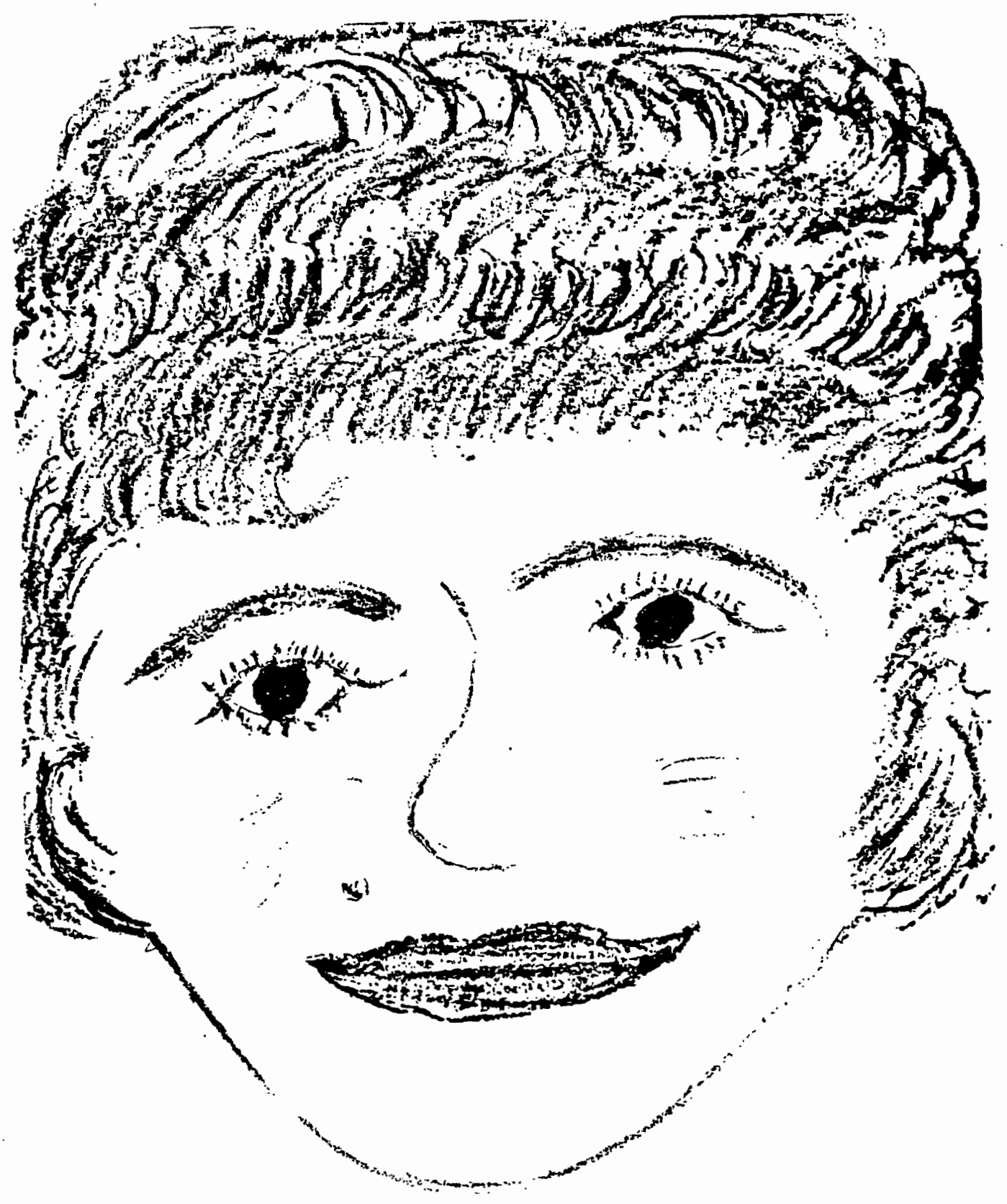

Figure 5. Self-portrait: subject 6, Age 65 . 


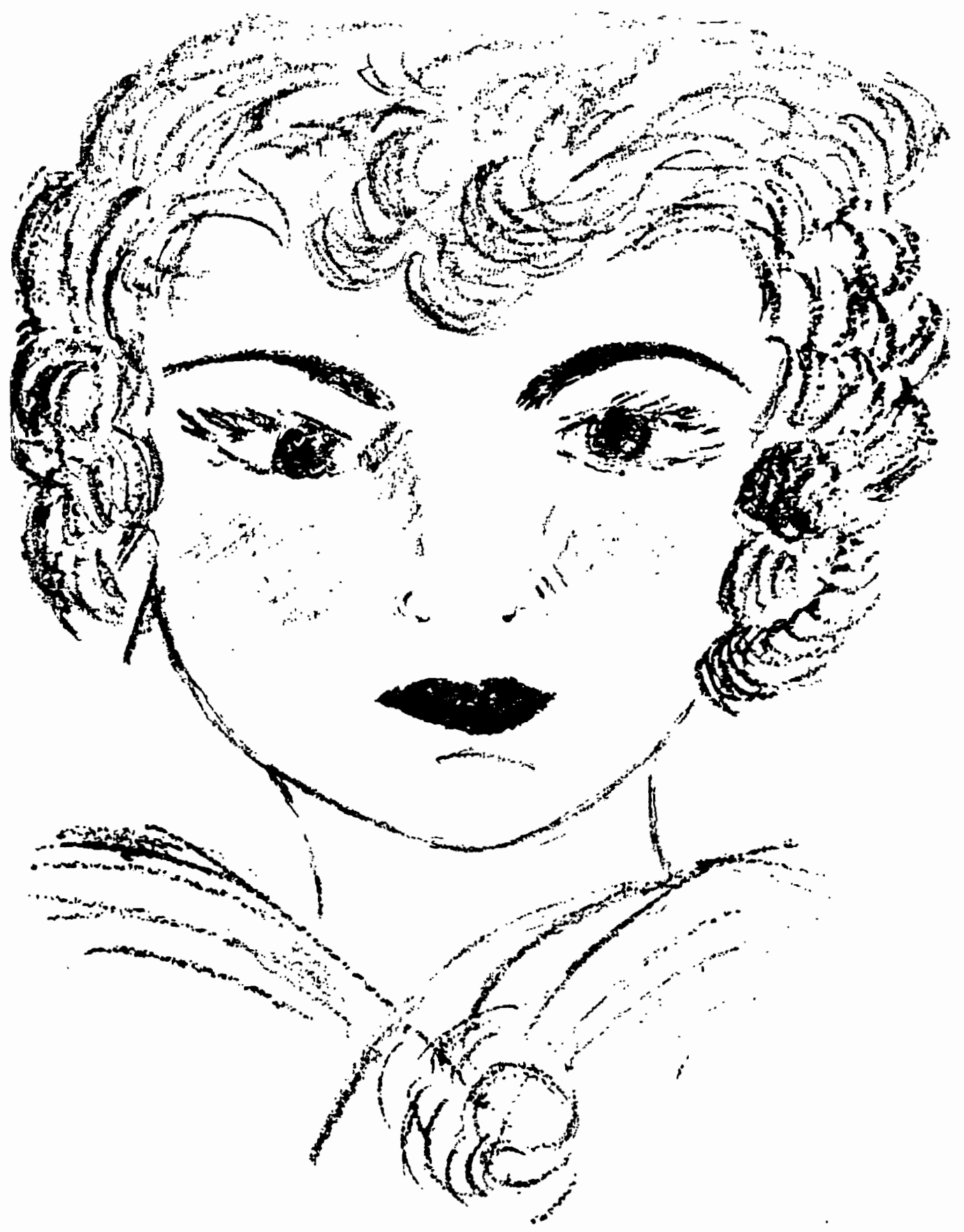

Figure 6. Self-portrait: Subject 7, Age 62 


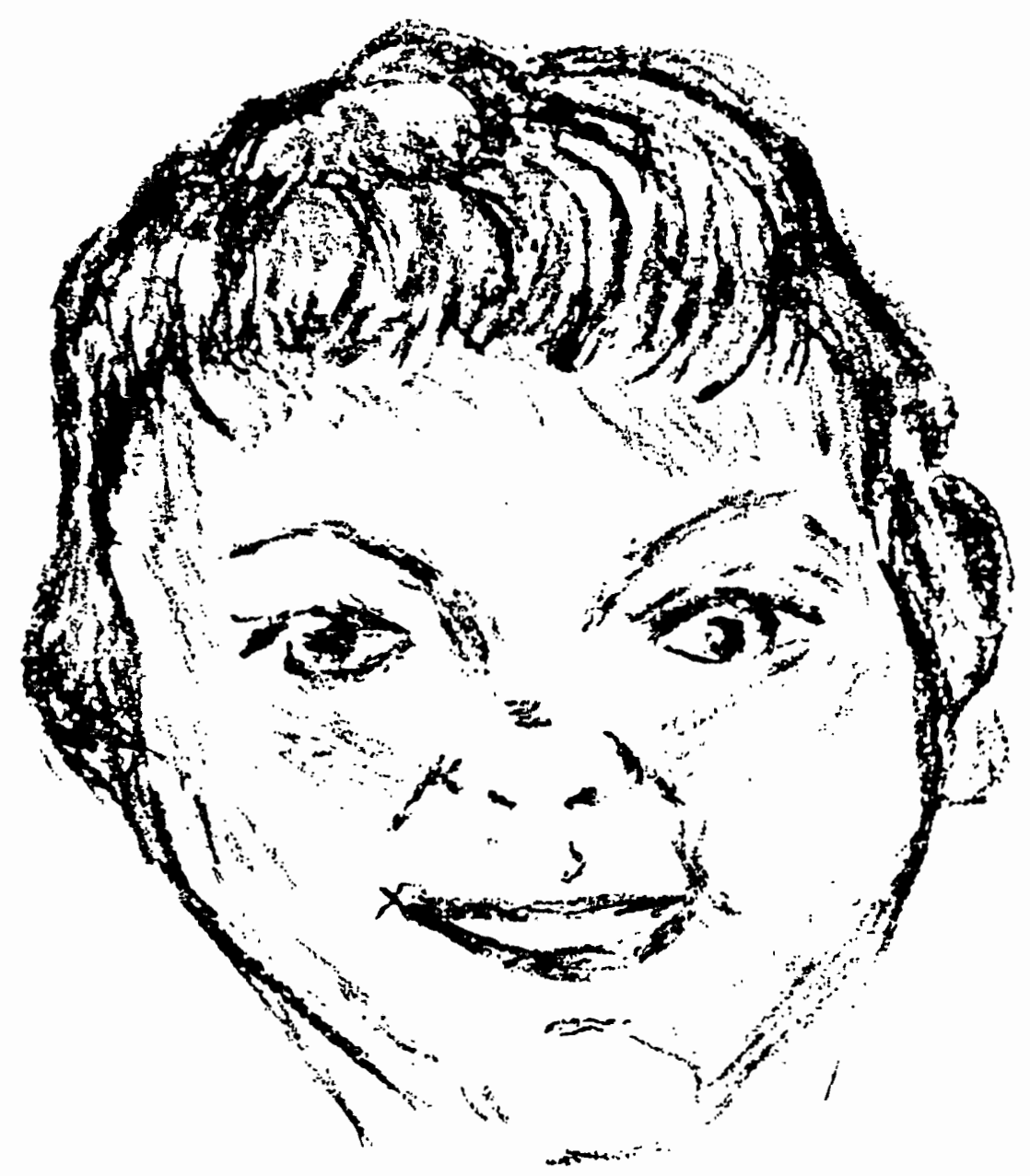

Figure 7. Self-portrait: subject 10, Age 61 . 
of drawing an accurate portrait--she wanted it perfect, and thus experienced a great deal of frustration. Finally in exasperation, she exclaimed that if she had to produce an exact likeness, she would use a camera. This comment triggered empathy from the group and a great deal of laughter ensued. Subject 10 noticed when talking about her artwork that she had spent considerable time on the hair. Her hair has always been a concern to her--it is so thin that she spends much time creating hairdos which will maximize the minimal volume. Art Therapy Group: Session 2. This session started off with everyone more relaxed and wondering what the assignment would be. They shared with each other how much fun the first session had been, and how wonderful it was to be able to share inner feelings with others and not be afraid of censure.

Figure 8, subject 1, age 78, depicts a woman who finds it very difficult to talk about herself. Her stick figure picture representing significant others in her life shows herself as "Mom," her deceased husband as "Dad,", and her three children. Her husband died ten years ago and she chose to draw a time when they were all together. It is interesting to note that the husband's eyes appear closed in the picture which could denote he was deceased. She shared her son's (age 50) bout with cancer and stated that normally she does not share troubles with people. The group responded by remembering her husband as a talented singer who had been in the Swedish Men's Choir for 45 years. This was a pleasant memory for her.

Subject 2, age 73 (Figure 9), drew a picture of her mother and father along with her siblings. This exercise brought back painful yet joyful memories of a time when her life was dramatically changed. Her 


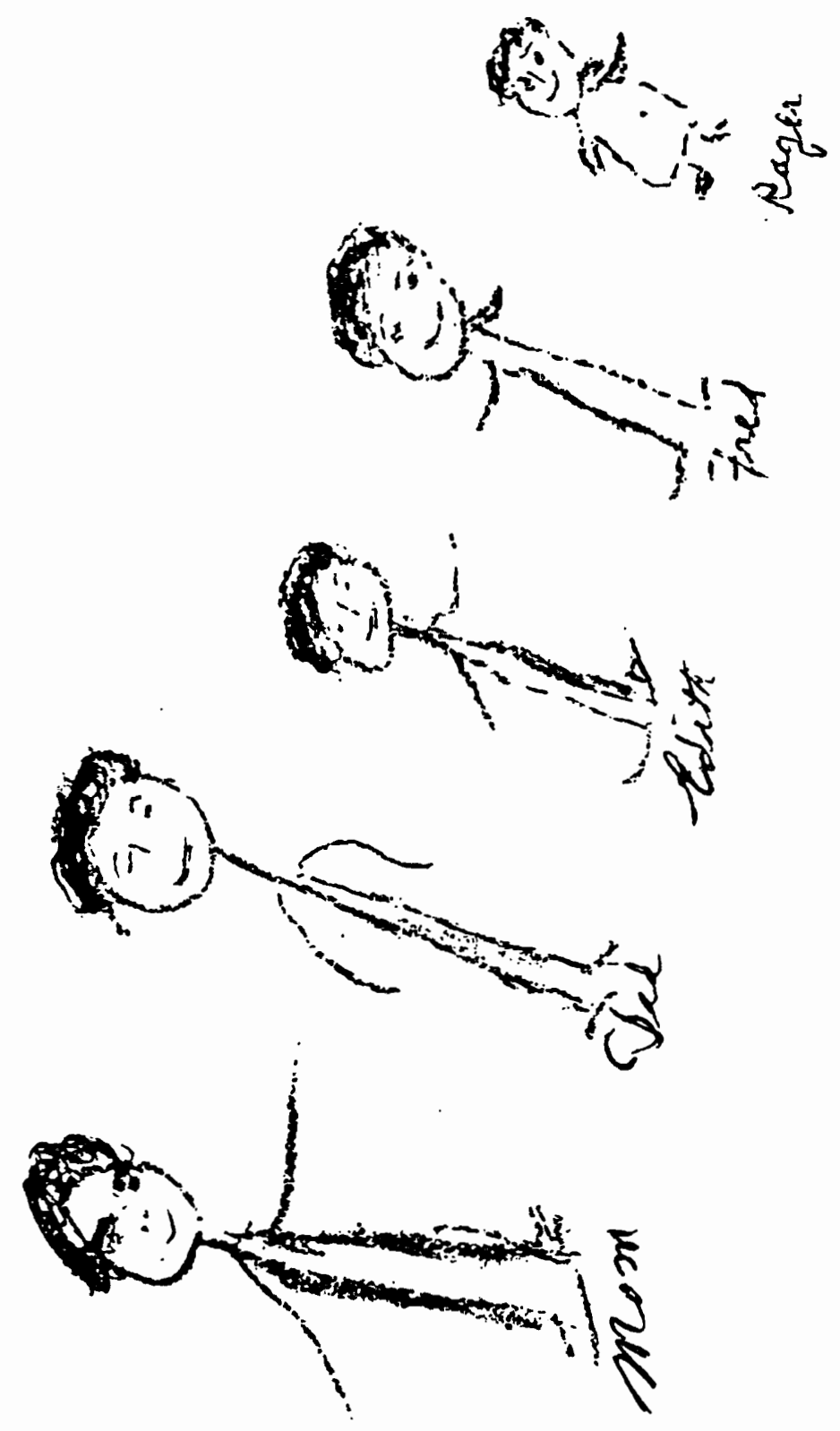

$\stackrel{\infty}{\sim}$

䓍

i

芩

永

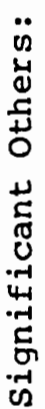

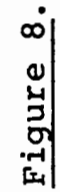




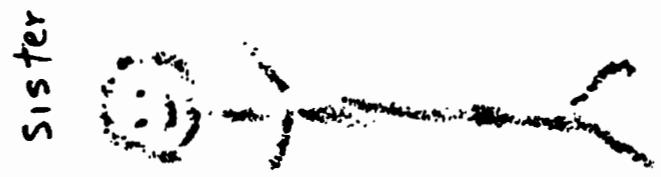

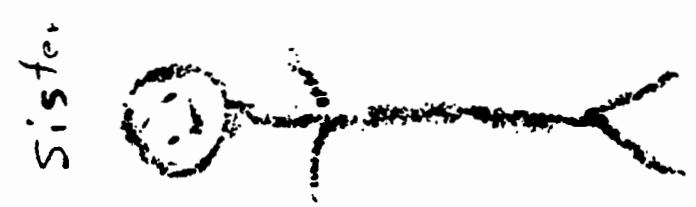

$n$

$\stackrel{\circ}{\circ}$

N

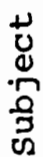

$\stackrel{\frac{1}{\sigma}}{L_{1}^{\circ}}(1,0)$

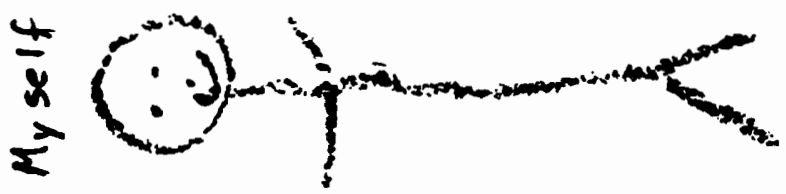


father died when she was ten years old. Her sisters were 2 and 4 (a twin sister died at birth). Her father had planned to send her to college to major in music. When he died there was no extra money, so she settled for a teacher's college. She had made a death-bed promise to her father that she would be her mother's helper, thus, she assumed much responsibility early in life. She recalls her family as always being close; her two sisters are still living and get together whenever possible. Subject 2 revealed that she has always wondered how different her life might have been had she gone on to pursue a music career, but added that she does not have any regrets--one does what one has to do. Subject 5, age 61 (Figure 10), drew three important groups: her husband and herself with their children, her parents and herself with her siblings, and her painting class. Before the verbal sharing portion of the session, she was bothered with trying to correct the "messy" job she had done on her brother who died at the age of 22 in 1949. As the group began to share their pictures and the memories associated with the pictures, she suddenly realized what had happened in her drawing. Not only had she messed up her brother's stick form but had also tried to correct her stick form in the group representing her present immediate family.

She began to cry and commented that she didn't know what was wrong with her, that she almost never cries and especially would not cry in public. She said her brother was killed in the great forest fire in Montana in 1949 and she felt responsible for his death. When Subject 5 and her husband set up housekeeping in Montana, they were quite removed from their families in the East. She persuaded her brother to live with them and attend college in Montana. 

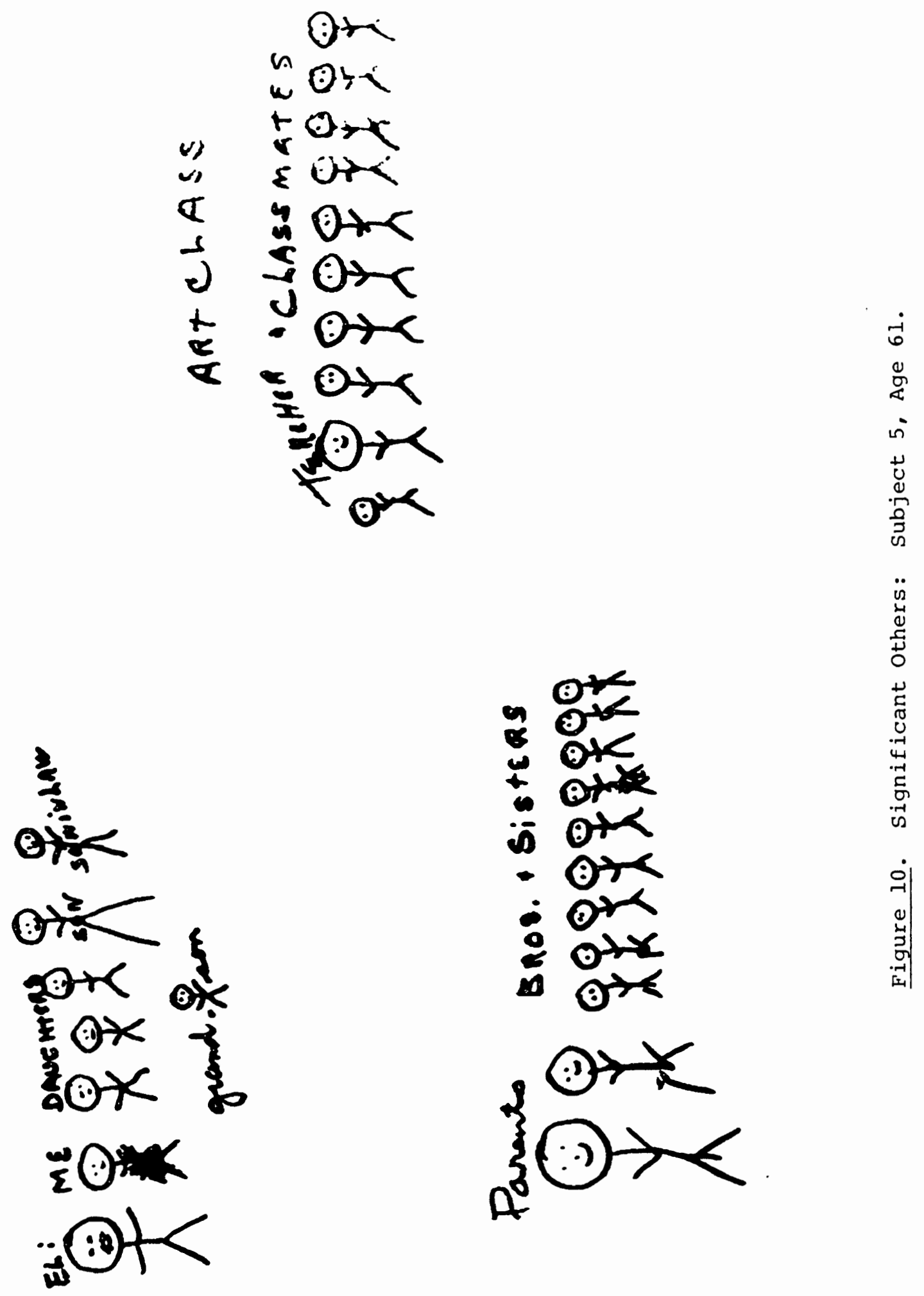

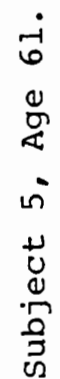

范 
Her mother had not wanted the son to go to Montana and "get burned up in a forest fire" (the son worked for the Forest Service). But Subject 5 persisted and the brother moved to Montana and lived with them.

The brother and 13 other young Forest Service employees were downed in an airplane while fighting a fire. The subject felt the "bureaucrats" had bungled the fire-fighting directions and caused what she considers mass murder even to this day. She shared some photographs and wept quite unashamedly and then was embarrassed; she had wept only once in these 30 years and then in private. She had not shared her burden of guilt with anyone. In her weeping, she cried out that her brother would be alive today had she not persuaded him to live with her. The group responded with great sympathy. Two members of the group were originally from Montana and offered many alternative steps she might explore if she wanted to sue the Federal Government even at this late date. Other members of the group talked about losses of family members at early ages and the impact on their lives. The group discussed grief reactions and subject 5 said she felt a great relief. She had never had an opportunity to express this secret guilt nor to grieve openly. Her mother had told her at the funeral not to cry. The real value of group support was shown not only in all three sessions for all subjects, but is clearly demonstrated in this instance. The experimenter checked with Subject 5 after the session to make sure she was all right. The subject responded that the group allowed her to get all those feelings bottled up inside for 30 years out in the open so that she could look at them realistically. She also said, and this was also expressed by other group members, that when something so guilt-laden is bothering a person, that it takes time to share it with 
another and many times you find no one wants to listen. This reduction of repressed emotion made the whole involvement in the study worthwhile for the subject.

Subject.9, age 66 (Figure 11), filled her picture with lots of friends and neighbors in addition to family members. She said she had not been aware of adding all the friends until the group sharing had started. Since she lives alone, and a great distance from her family, she is more interested in her friends and neighbors than she is in her family.

Subject 10, age 61 (Figure 12), looked at her picture and began to cry openly and emotionally. The group waited and the subject shared that this picture triggered a pleasant but sad memory. The time is 1960 when her sister's husband died and left her with four small children. The subject stated she had not thought of this particular incident for a long time, but just seeing it depicted on paper even in stick figures brought back all the pain of loss. The experimenter checked with her by asking if it were a pleasant memory even though emotional, and she replied, "Oh, yes. We are an extremely close family and find every opportunity we can to get together." Her sharing evoked great empathy from the group and they shared some painful yet pleasant memories. The group members agreed they would not want to lose memories that are painful, that somehow the painful ones go along with the joyful memories.

Art Therapy Group: Session 3. The subjects approached this last session with some sadness--they all said they were sorry it would be over. It had been a rewarding experience to participate in exercises 


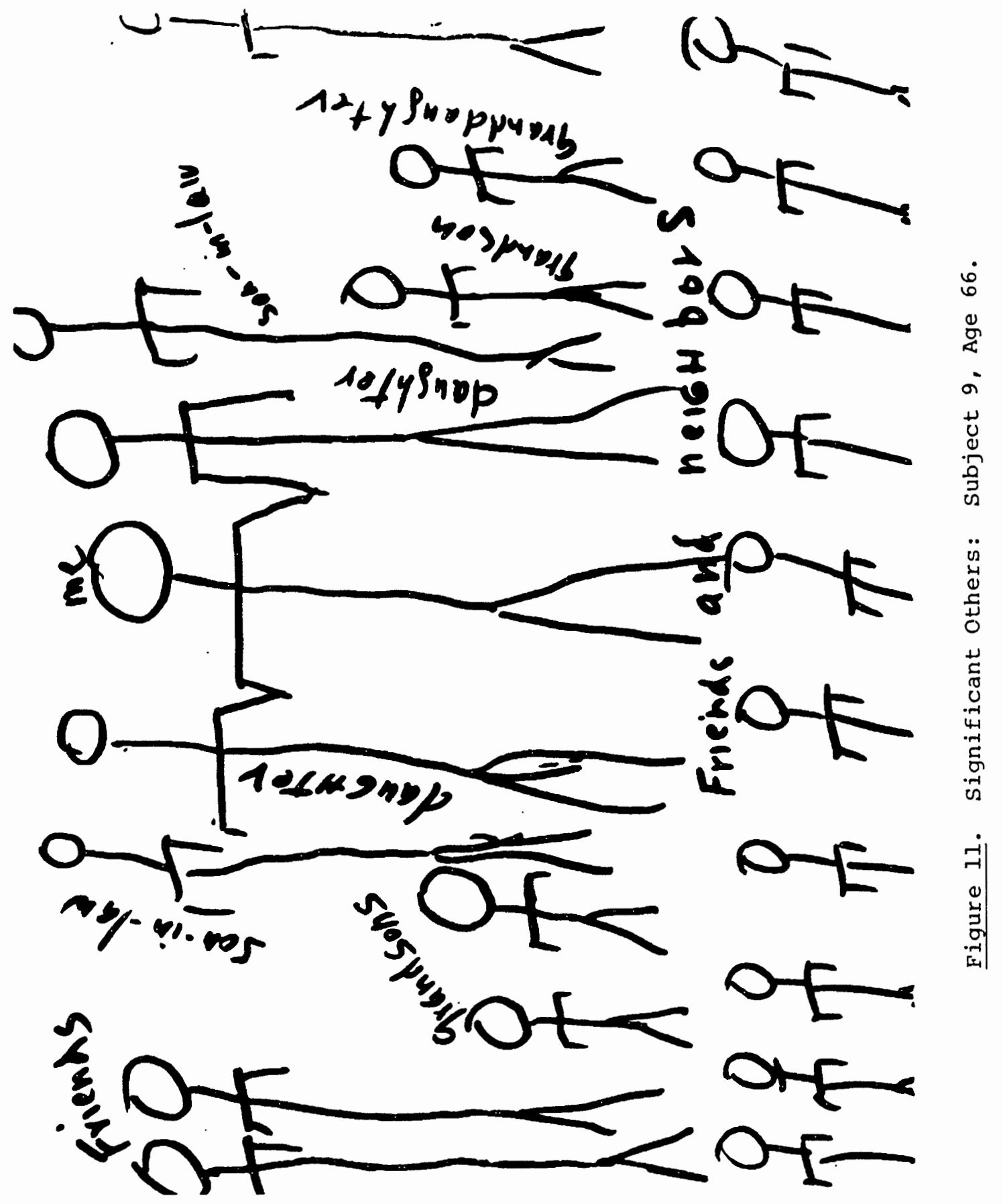



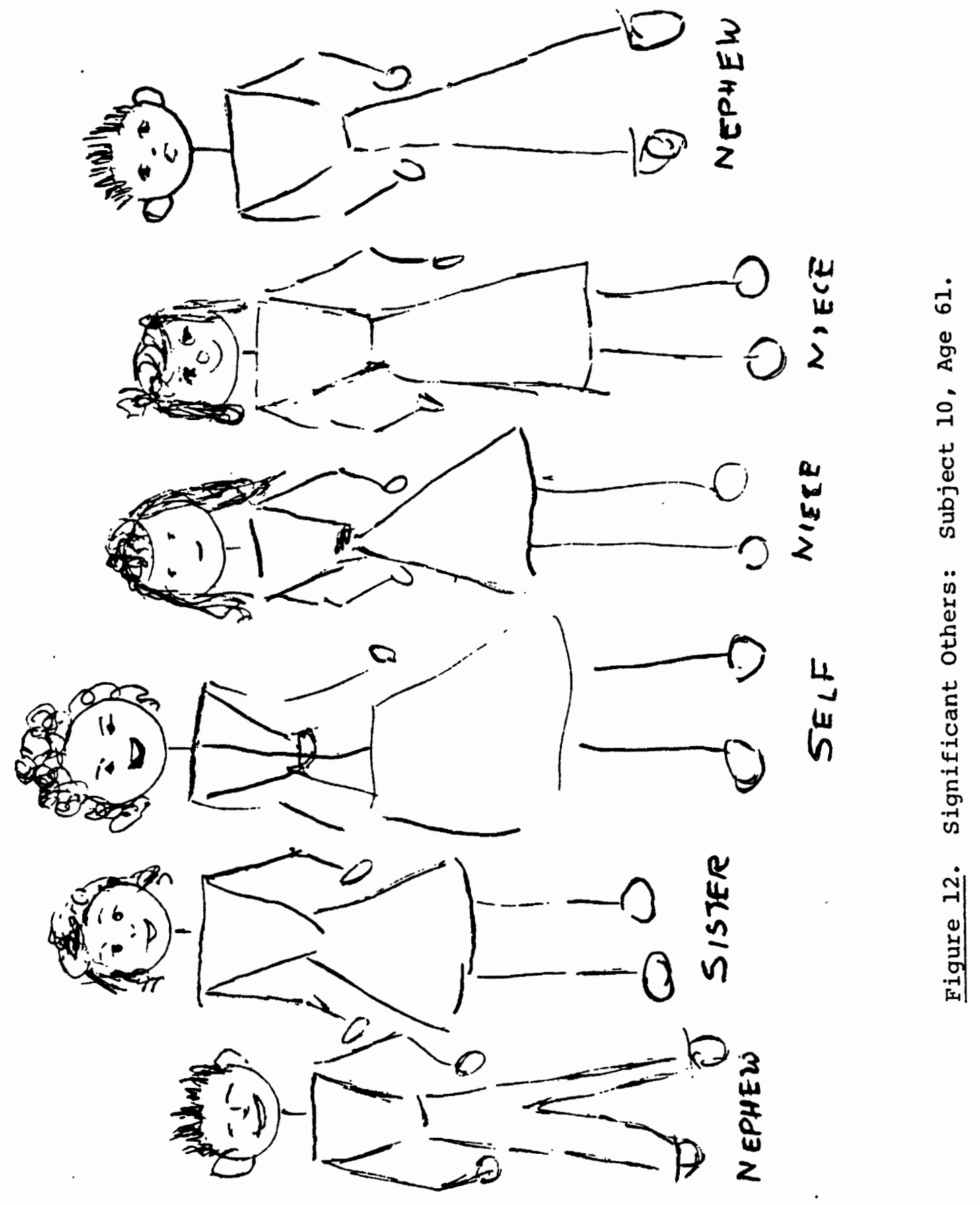
that focused on different aspects of themselves and their environment. Subject 1, age 78 (Figure 13) laughed and said she felt like a school kid again. Her mandala represents three important areas in her Iife: home, church, and flowers. The home to her is important to all family members and she was the mainstay in the home, although the father of the family represents stability. The church in her world view represents security and the two bouquets of flowers show that we all enjoy the beauty of nature. She felt it was easier to talk about this project because she is too timid to talk about herself. She bent her head and in a soft voice said, "I have always suffered from an inferiority complex." The group responded that while she was shy, she was warm, loving, and giving, and that while she was humble, she radiated vibrance and strength. She expressed the joy in the opportunity to araw symbols of what was important to her.

Subject 2, age 73 (Figure 14), said she had no definite design in mind but loved working with the colors. "I don't know what it says about me (laugh), but maybe I'm going around in circles." Then seriously, as she examined her artwork, she said that perhaps each band depicts certain areas of her life--each one more fulfilled than the previous one. She also noticed that she had not used any grays or browns, just nice pretty colors. One member of the group responded that she had put the sun in the center with a red dot in dead center. The subject began to muse as to why she might have put a red dot in the middle of the sun. But one member of the group said that not everything has to be perfect, that reality was not perfect. Subject 2 expressed joy with her creation and gained an insight into her own makeup. She also said the joyful colors represent joyful living and 


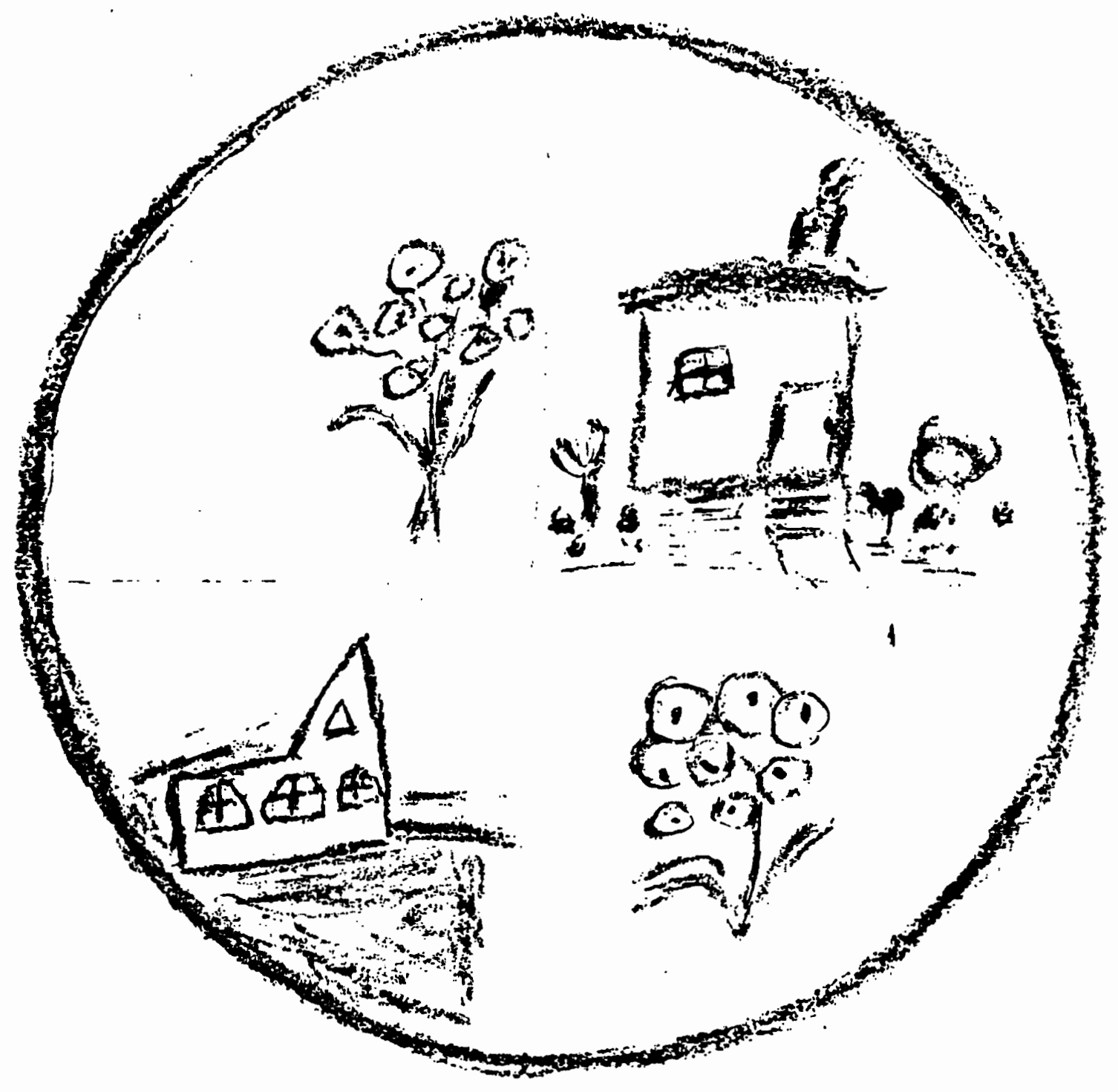

Figure 13. Mandala: Subject 1, Age 78 . 


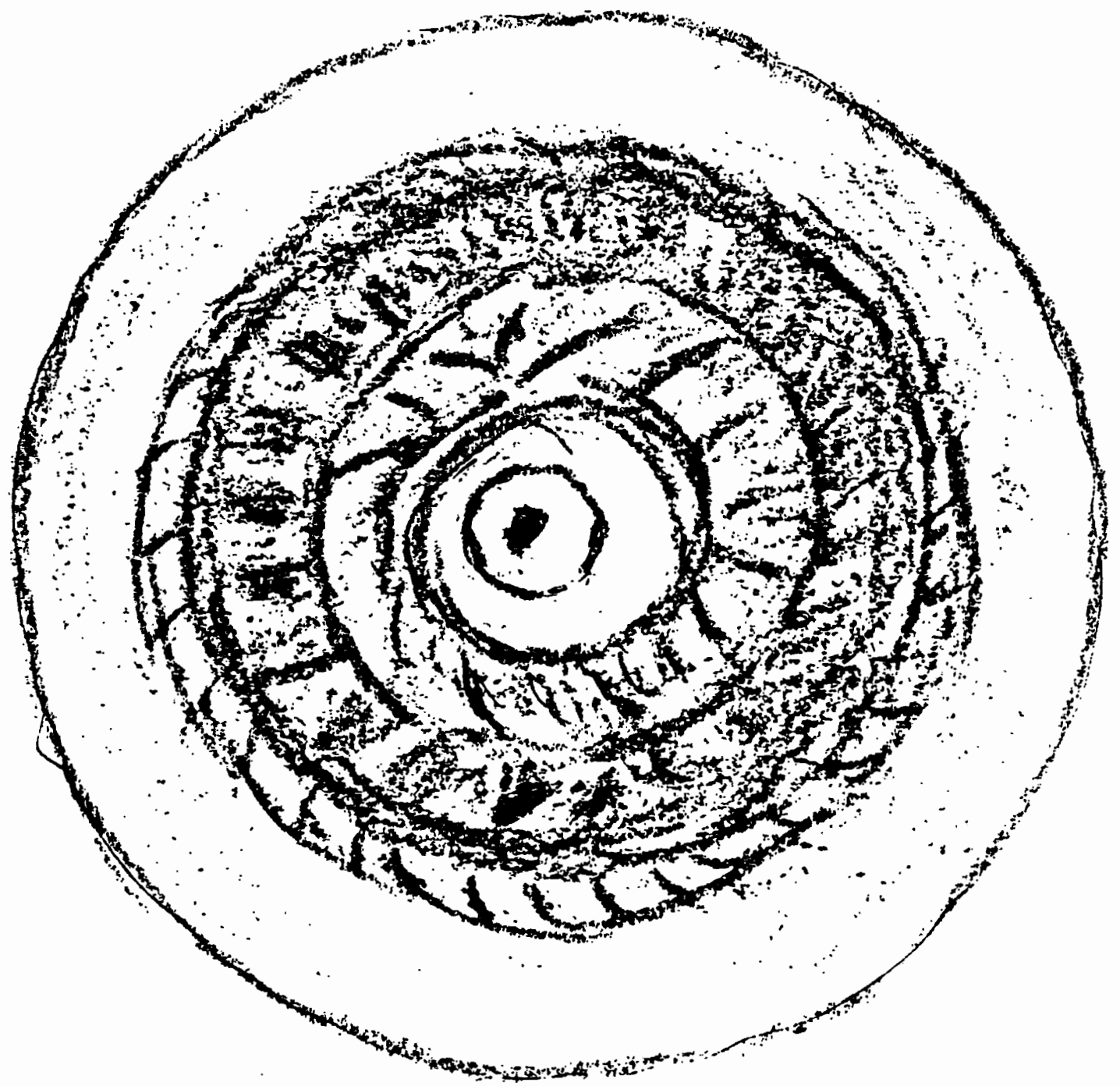

Figure 14. Mandala: Subject 2, Age 73. 
all good things that have happened to her and all the good friends that have enriched her life.

Subject 3, age 75 (Figure 15), was glad the group did not have to draw people today. She said she had been depressed after the last session with all the sadness that had been evoked from the art project. This subject had lost her husband recently and perhaps many of her comments center on trying not to talk about any event that is sad. This hazard had been provided for in the design of the study. The subject had contacted the experimenter during the week so we were able to talk about her reactions.

Subject 3 's mandala reflects the sun shining and the will to create a happy world. She said she was determined that today would be a happy day and even though she couldn't draw and did not want to draw, she would and did create a symbol of joy--she included two "bluebirds of happiness" to make sure she would succeed. This appears to support Jung's (1977) statement that the world we create is largely determined by the model we choose.

The group responded to subject 3 by telling her that sometimes when we hear other problems, we don't feel so alone. The response by Subject 3 was that perhaps her sadness came from a feeling of being inadequate in helping the person in need.

In Figure 16, subject 5, age 61, was not sure what her mandala represented. With her elaborate border, she wondered if she felt her life was confining. She did not know who the figures represent--she did not know if this represented one person either trying to get in or trying to get out, or if this represented two separate-figures in her 


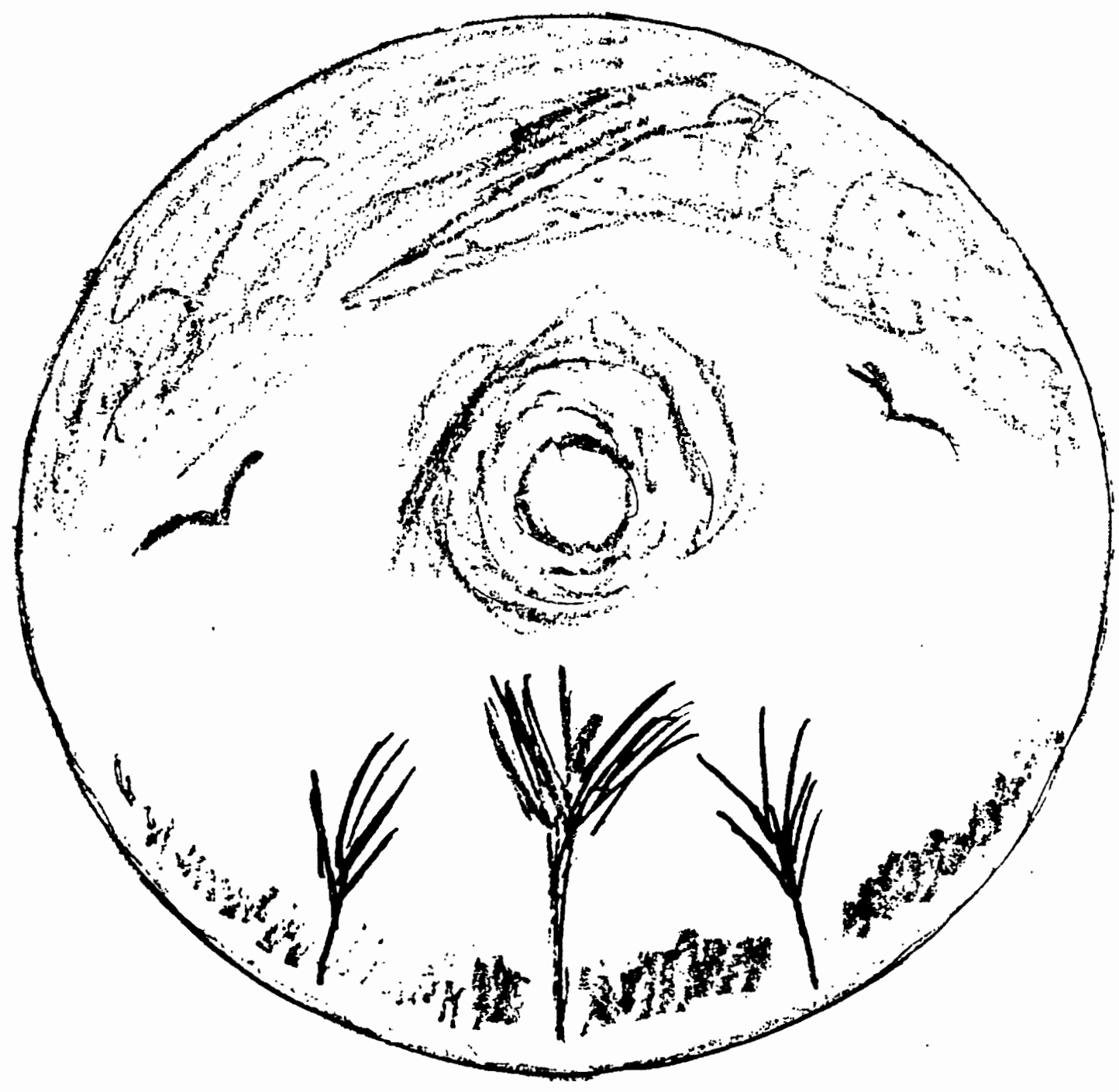

Figure 15. Mandala: subject 3, Age 75. 


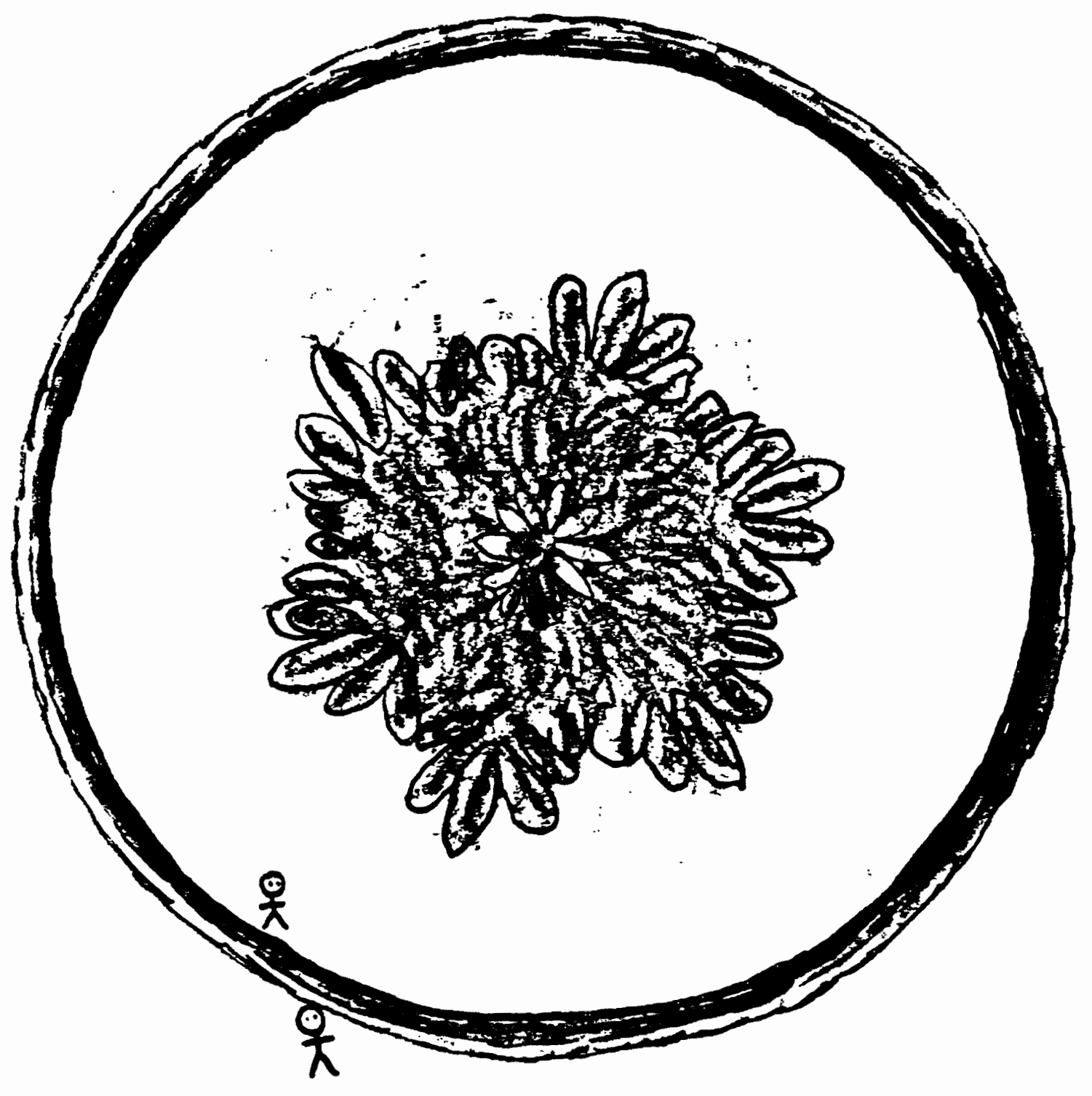

Figure 16. Mandala: Subject 5, Age 61. 
life. The group responded to her mandala by saying it looked like fine porcelain.

Subject 6, age 65 (Figure 17), divided her world into ten separate parts: family, church, friends, projects and volunteering, trips, home, communications, reading, work, and nature--God's world. This woman retired last year and has structured her time so she has varied experiences to look forward to. The group was intrigued with this mandala and thought it was very clever.

Subject 8, age 67 (Figure 18), was not sure why she drew what she did. "As I examine it more closely for some pattern," she said, "I discover movement. I am a positive and action-oriented person and always welcome new experiences. I see action in my mandala in the butterflies, the waving grass, and moving clouds. It is interesting for me to note the flower in picture which resembles the shooting Star from my home state of Montana." The group liked her vibrant and happy design.

The group members said they had gained many new insights from executing the mandala and that much of the time we never get below the surface in our interactions with others. When we do, we get embarrassed. The consensus of the group was that this was a valid exercise to give them a new perspective of their world and themselves in their world. One member said that.we amaze ourselves when talking about things that we had no intention of talking about and/or sharing. 


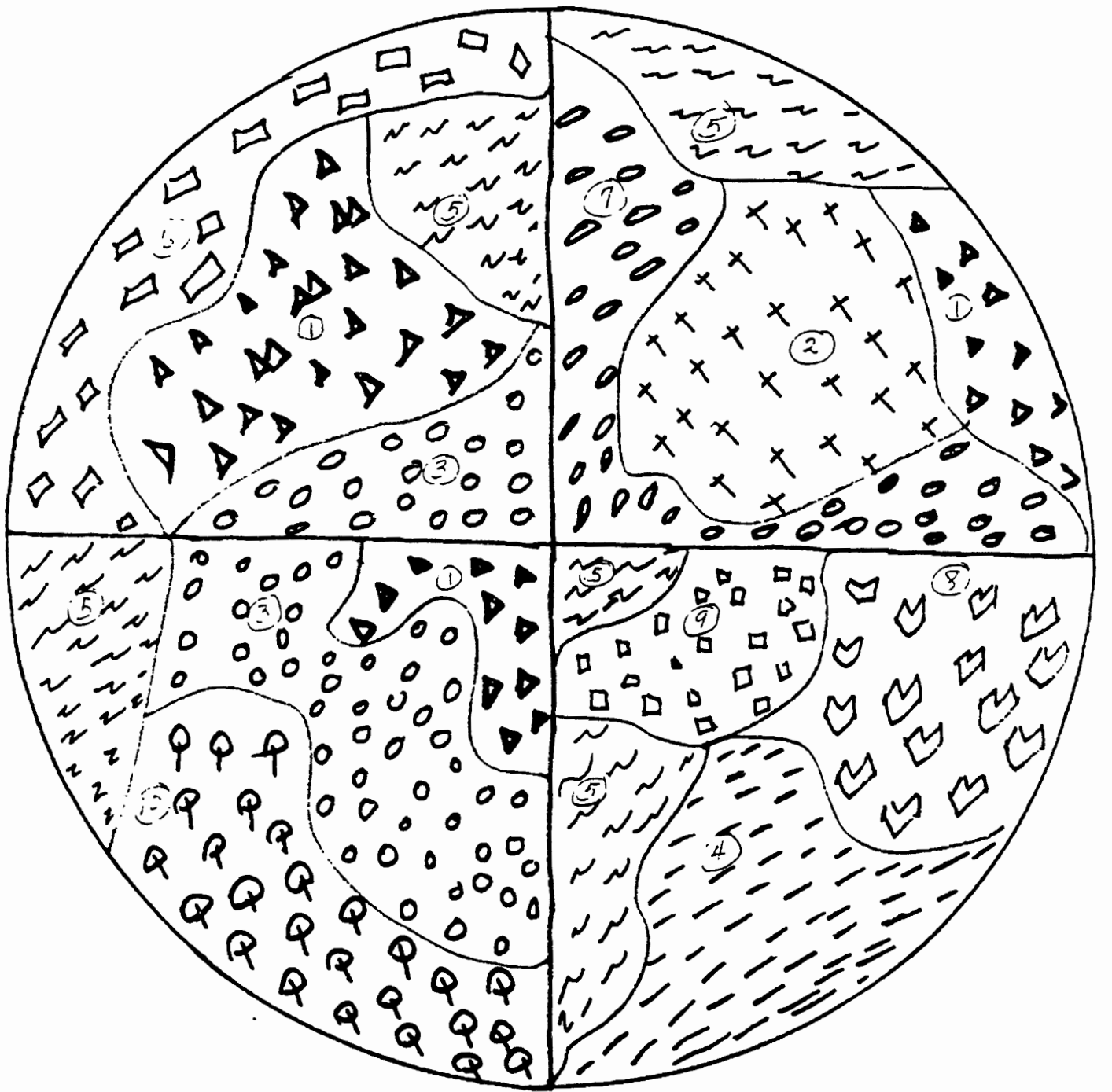

Legend: (1) family

(2) church

(3) friends

(4) projects, volunteering

(6) home

(7) comunications

(5) Trips

(8) reading

(9) work

(10) nature - God's world

Figure 17. Mandala: subject 6, Age 65 . 


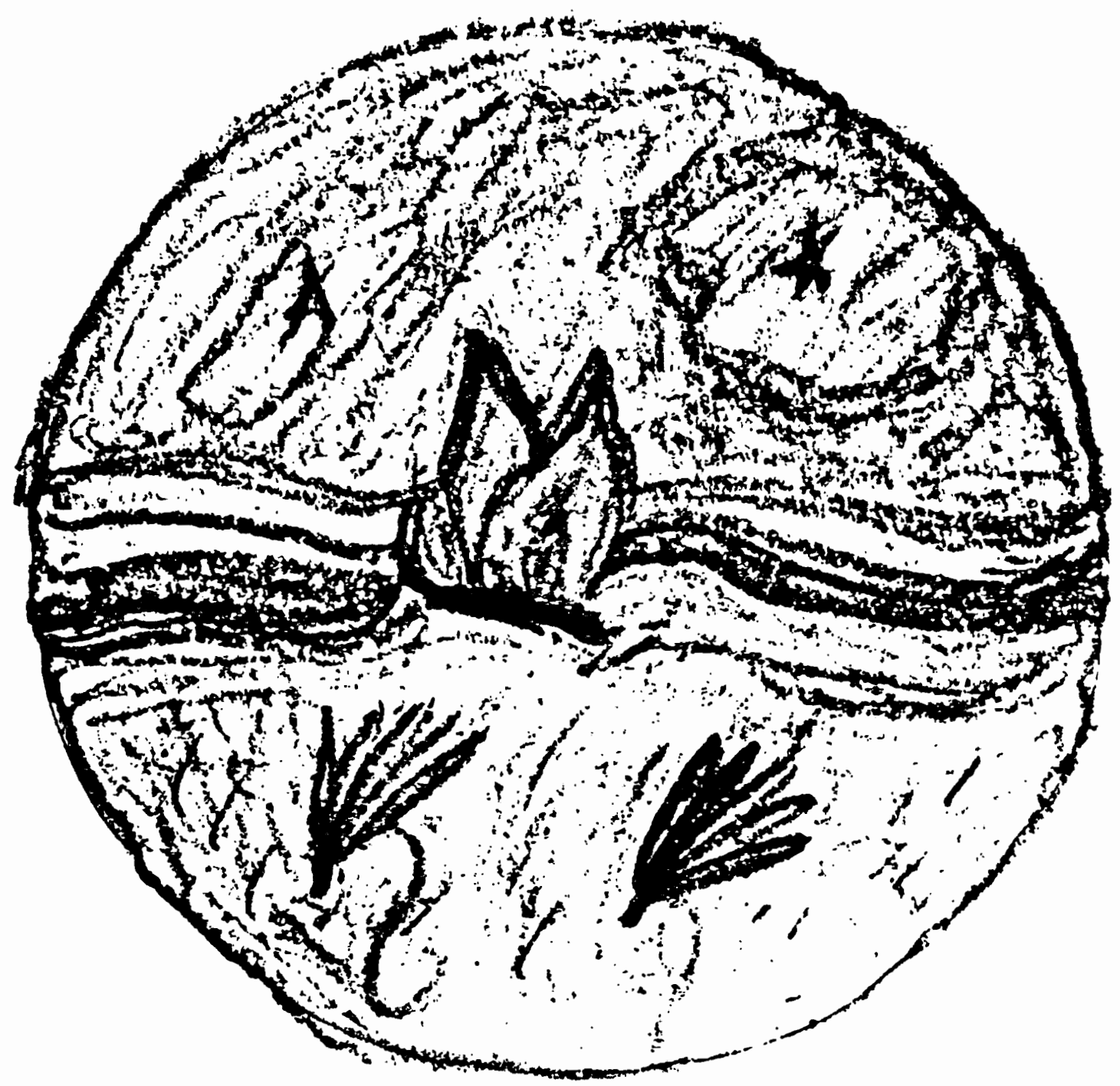

Figure 18. Mandala: Subject 8, Age 67. 
The topics for discussion were decided for each of the three sessions by the group, although it was found that a more active role than expected was required on the part of the experimenter to suggest suitable topics. This factor supports McGee and Lakin's (1977) stance that "gerontological psychotherapy usually requires an active role on the part of the therapist" (p. 333) .

The experimenter promoted discussion by introducing questions which encouraged informal life reviews. Some of the topics dealt with during the three weeks were:

1. Describe the earliest conscious awareness (memory) of self. Most of the subjects were able to quickly recall an episode back to approximately the age of three. It is interesting to note that each sharing was prefaced by stating the geographical location of the event.

2. Describe what you see when looking into the mirror. The subjects responded by revealing aspects of physical changes that they disliked, worried about, etc. This question was patterned after the Mirror projective test outlined by Butler and Lewis (1977).

3. Reflect on the meaning of death. The consensus of the group was they did not fear death, that it was part of living. The subjects felt there was a generational gap in the elder person relating to a younger person in this area of life. Many members recalled earliest death and funeral encounters. Much time was spent outlining steps the subjects have taken or are taking 
in "putting their house in order," i.e., giving away heirlooms, etc. The subjects unanimously agreed this adds to a sense of well-being--they no longer wish to accumulate treasures for the relatives or friends to dispose of.

4. Do you spend time in introspection? A discussion took place about the difficulty of honestly answering questionnaires, such as the pre-test. Most of the members stated that they have never really looked at themselves. After the three sessions were over and the post-test was given, some of the members laughed and wondered if they would be more objective this time; many subjects felt they had been inclined to answer the pre-test by what they thought others thought of them.

5. Think of a significant moment in your life, past or present, that was particularly meaningful to you and tell why it is so. Most of the subjects brought photographs to share with the group. This triggered a great deal of discussion about the event in the photograph and the people who were in the photograph. Many pictures were of reunions, either family or fraternal organizations. One member stated she used to like reunions but not anymore--it seems the numbers are increasingly reduced with each reunion, and this is not a pleasant reminder of the inevitable passing of all human beings.

6. How do you react to names given to people in later life? A lengthy discussion took place over the negative names 
ascribed to older people. The group members objected quite vehemently to words such as "senior citizens," "the elderly," "senior adults," et cetera. It was the opinion of the group that they were people who had just lived longer. One member pointed out that this negative stereotype could be a reason why some older people are unwilling to seek needed services and social activities. These comments support Bennett and Eckman's (1973) view of the negative aspects of the aged person. Bennett and Eckman report cross-sectional studies of the self indicate that old people have more negative views of themselves than young people have of themselves. "Morale and life satisfaction are attitudes reflecting evaluation of one's surroundings and one's life circumstances" (p. 577).

7. Who influenced you the most during your lifetime? This was a very pleasant topic of discussion. Most of the subjects said one or both of their parents had the most influence on their lives.

The author presents the following case to illustrate a sharing of selfhood and the value of the opportunity to reminisce: In recalling the earliest conscious memory, one man who was severely crippled by polio at the age of five, recalled a memory prior to that age. His eyes shone with a sense of happiness as he recalled a time when he ran on two good legs. Here was a man who is noted for taciturnity who shared a memory which he had never shared before--not even with his wife. When asked how he felt about sharing such a happy time in his 
crippled life, he replied, "I feel good." This sharing, this opening of the doors of the unconscious, brought back a part of self that wasn't always fettered. Future sessions found him eager to talk, eager to be part of a group (an activity he seldom had indulged in during his life)--a group which allowed him to see himself as whole. The sharing of one member opened doors of memory for others. Many members stated they were surprised that they felt it was all right to share in a group some emotional memory they had not shared with anyone. It appears it is not the experimental model, the "science" that counts here, but the prima facie evidence that various individuals have opened up, have been helped clinically. 
CHAPTER IV

DISCUSSION AND CONCLUSIONS

It was hypothesized that art therapy with the elderly would increase the quality of an informal life review and motivate them toward greater psychological well-being (life satisfaction). To test this hypothesis, 30 subjects between the ages of 61 and 83 were assigned to three experimental conditions: Art Therapy Group, Discussion Group, and Control Group.

Most of the differences between the three groups were statistically non-significant in the improvement of life satisfaction as measured on the Life Satisfaction Index-A (ISIA). However, in testing the differences between groups, the Mann-Whitney was significant in one analysis.

In comparing the Art Therapy Group with the control Group, the Mann-Whitney only approaches significance using a two-tailed analysis; however, the results are significant when using a one-tailed test. The difference between the Discussion Group and the Control Group, while not significant, is in the predicted direction. The difference between the Art Therapy Group and Discussion Group is clearly nonsignificant. This suggests that both groups had improvement in LSIA between pre-test and post-test scores and that both the Art Therapy and Discussion Groups are viable techniques for increasing psychological well-being in later life. It may also mean that involving older people in any way is good "therapy." 
The interpretation of this study can be approached from another perspective, i.e., from a discussion of the outcome of the groups. The qualitative analysis points toward a need for developing programs not only for nursing homes and/or clinical settings, but for healthy individuals in later 1ife. It is the author's belief that it is imperative for society to respond to the needs of particular groups of people, not by "treating symptoms" but by providing the opportunity for actualizing and fulfilling their capabilities and for helping them to find deeper and more satisfying meanings in life. This position is supported by Fromm (1941, as cited by Schultz, 1977) who believes that "whether a personality is healthy or unhealthy depends on the culture which fosters or thwarts positive human growth and development" (p. 40). Other practitioners and gerontologists make a plea for society to aggressively and creatively develop innovative therapeutic services for the elderly which would lead to more effective and adaptive methods of coping with losses related to reduced physical, mental, social, and cultural capacities. The focus of therapy on the aged should be toward helping them find a sense of identity, autonomy, and fulfillment (Birren \& Woodruff, 1973; Davis \& Klopfer, 1977; Eisdorfer \& Lawton, 1973; Gurland, 1973; Ingebretsen, 1977; Jarvik \& Cohen, 1973; Krasner, 1977: Lawton, 1973; McGee \& Lakin, 1977; Nouwen \& Gaffney, 1976; Riegel, 1973; Zubin, 1973).

This writer cautions that art therapy, as outlined in this study, should only be used as an adjunct to the psychotherapeutic process. It is a modality not applicable for all people, or a panacea for all problems. Furthermore, art therapy should only be used by those therapists who are knowledgeable and skilled in its application. 
This study demonstrated outcomes as follows:

1. There was an observed and verbally shared increase in life satisfaction of the members in both experimental groups, Art Therapy and Discussion.

2. The study provided the writer an opportunity to develop, and test the effectiveness of a therapeutic technique which may be implemented in other settings, both for healthy individuals and those with psychopathology. To develop new modalities of therapy for the aged, Lawton (1973) stressed that "unless we ask the older person how he feels, we shall not really know how best to administer treatment, whether through reassurance, behavior therapy, occupational therapy, or group activity" (p. 342).

3. The memories evoked through Art Therapy were qualitativeIy different from those of the Discussion Group. The memories brought to consciousness through art activities appeared to be more painful and the kind which could require intervention such as psychotherapy.

4. The systematic opportunity of a life review in both groups was a satisfying experience (as reported by the subjects), and the following benefits were observed by the experimenter:

a. Identification: The subjects in both groups, consciously or unconsciously, identified with each other as life episodes were shared--one 
subject's sharing triggered old forgotten memories of other members. At times there appeared a breathless eagerness to share experiences. b. Catharsis: The subjects' feeling of emotional release resulted from the group sharing.

c. Insight: The members shared with the experimenter that they experienced new insights into themselves--looking at themselves in a way they had never done before. The group process allowed for greater acceptance of self as well as a feeling of being accepted by others. The subjects as a whole had never allowed themselves to challenge either themselves or others in this respect.

5. The lack of significant difference between the Art Therapy Group and the Discussion Groups, suggests that benefits are consistent with the position that continued social involvement of any $k$ ind is beneficial to the morale and well-being of people in later life (McGee \& Lakin, 1977; Neugarten, Havighurst, \& Tobin, 1961).

6. In the Art Therapy Group, the person who did the drawing had the opportunity to recognize it as his/ hers and then was first to talk about it. The group was generally quite supportive of each other and criticism was lacking throughout this study. The 
comments by group members gave recognition that each person had done his/her best. The group laughed easily at themselves and with others. This supports Rogers" (1961) notion of group sharing of artwork, i.e., that an individual once having created, "desires to share this new aspect of himself-inrelation-to-his environment with others" (p. 356).

7. The whole experience in the Art Therapy Group was designed to encourage a sense of identity and selfworth through both the art activity and the group process. The study reveals that as the subjects were willing to disclose themselves through their artwork, a new sense of identity was experienced. The members stressed the importance of trust as prerequisite to the expression of feelings they had not shared before.

8. There is an obvious and pragmatic advantage of art therapy in a psychotherapeutic group setting versus art therapy as a group activity. It is that potential emotional problems exist which might emerge during artistic expression. During the course of this study, there were two situations in which the experimenter was required to attend to emotional reactions: (a) One member experienced depression after the second Art Therapy Group session after certain emotional memories were shared by others, and (b) and a second member, during the same session, shed a 30-year secret 
burden of guilt. In both cases the experimenter immediately spent considerable time with the individuals to avert any long-lasting deleterious consequences.

9. Another area where art therapy is better carried on in a psychotherapeutic setting would be in regards to the handling of self-portraits. Most selfportraits are executed with the subject's own image of self, and when confronted with a new reality through the drawing and group sharing may experience some lack of confidence in reaching toward emotional growth. In a psychotherapeutic session, this exercise could be expanded upon to allow a person an opportunity to gain further insight into his/her own psychological makeup. There are several possible sources of uncertainty in interpreting the results. The outcome of this study could have been confounded by overly high pre-test scores. This could have been due to a "cohort" effect. Many of the subjects were of Scandinavian descent and life-long church membership, where self-disclosure has not been the norm. This would lead one to question the honesty with which the subjects answered the pre-test LSIA. At the end of the sessions, members of both groups commented on the difficulty of answering such personal questions as appear on the LSIA. Many agreed that they had a tendency to answer in the light of how they thought others saw them; to give "socially desirable" answers. The experimenter got the impression that the pretest scores may have leaned toward an artificially higher or more favorable assessment of their state of psychological well-being. The author believes, based on group discussion, that the post-tests would 
be a more accurate assessment of their true life satisfaction as based on the instrument of measurement.

Another possible confounding variable was the not quite random assignment to groups, although the Kruskal-Wallis proved the groups were similar at the outset. To support the method of assignment, it must be pointed out that the experimenter was not working with a captive group of undergraduate students, but a group of volunteers over 60 years of age. Investigators in gerontology must be aware of several factors in drawing a sample of relatively healthy individuals:

1. The potential subjects in this study, while interested in participating in research which could be beneficial to others, have an existing well-structured life with little room for long-range weekly commitments of time.

2. The subjects had to have some means of transportation to the site of research. A number of the subjects rode the bus, thus increasing their time commitment considerably.

3. The size of the group has an effect on the quality of sharing. Groups consisting of ten members became a problem at times in this study. It was not always possible for all members to share all they wished at any given session. The experimenter had to be attuned to cues of the more withdrawn members of the groups to insure they had an opportunity to speak. There were many occasions when a shared memory of one person triggered many responses and everyone 
wanted to reminisce at once. This factor could well be a confounding variable.

4. The short time of the study perhaps prevented more in-depth introspection, but a longer time was not possible due to the unwillingness on the part of the subjects to commit themselves for longer than three weeks. It is possible longer sessions may produce greater life satisfaction.

There are several areas in which replication of this study may be considered:

1. A pre- and post-Rorschach projective test could be used as a means of validating the ISIA self-report scores.

2. A longer time commitment may improve the in-depth introspection and ISIA scores of the subjects, especially in settings where the experimenter would be unknown.

3. A replication with the same population would test the variable of social desirability which appeared to inflate the pre-test scores in this study.

4. Before the results of this study can be generalized to other populations, this study should be replicated in other settings such as the Gray Panthers. Volunteers from this organization may be more likely to volunteer if they felt the study worthwhile and may be less dominated by cultural inhibitions which can be so powerful in some groups. 
5. To find out if religion contributes to the scores on the self-report ISIA, this study should be replicated in other church settings.

6. To see if age is a factor in the life satisfaction scores, the population of this study should be compared with a middle-aged group and/or a younger group.

7. It would be interesting, also, to compare the population in this study with a population evenly distributed with several age categories.

In summary, this thesis offers an alternative to addressing the issue of how to improve the quality of later life. It appears to the author that the group interaction in both the Art Therapy Group and Discussion Group did promote greater psychological well-being and the releasing of unconscious memories in the life review process. It appears that social interaction, whether in the Art Therapy Group or the Discussion Group, may be the primary medium through which a person comes to know himself/herself.

The author feels the study was successful not only in improving introspection and fostering a better acceptance of self by people in later life, based on the reports from the subjects, but the author had the opportunity to develop and test her own therapeutic strategy. The author's interest in art therapy stems from the belief that a patient often manifests a discrepancy between what he is able to communicate about how he feels and what he may be actually experiencing. A conscientious psychotherapist should avail himself/herself of all 
available modalities, to use as the occasion demands. A therapist needs to attend to all cues, both verbal and non-verbal in order to make a more accurate assessment of the needs.

The guiding philosophy in working with the elderly should be not what a therapist can do for the clients but rather how to be somebody with them (Davis \& Klopfer, 1977). With the elderly, all discovery and discourse are for naught if my knowledge neither cares nor gives, neither stimulates nor directs, neither solves nor alleviates the present plight of elderly people--their only crime being that they cannot stay the inevitable growth and decline that comes to every human being. 


\section{BIBLIOGRAPHY}

Adams, L. Analysis of a life satisfaction index. Journal of Gerontology, 1971, 11, 64-68.

Alexander, R. Determinants of well being: An analysis of environmental, social, and personal dimensions as related to well being in late life. Unpublished doctoral dissertation, Portland state University, 1979.

Anderson, F. E., \& Landgarten, H. Survey on the status of art therapy in the Midwest and Southern California. American Journal of Art Therapy, 1974, 13, 118-122.

Arieti, S. Creativity: The magic synthesis. New York: Basic Books, Inc. , 1976.

Arnheim, R. The art of psychotics. Art Psychotherapy, 1977, 4, 113120.

Bennett, R., \& Eckman, J. Attitudes toward aging: A critical examination of recent literature and implications for future research. In Carl Eisdorfer \& M. Powell Lawton (Eds.), The psychology of adult development and aging. Washington, D. C.: Anerican Psychological Association, 1973.

Birren, J. E., \& Woodruff, D. S. Academic and professional training in the psychology of aging. In Carl Eisdorfer \& M. Powell Lawton (Eds.), The psychology of adult development and aging.

Washington, D. C.: American Psychological Association, 1973.

Bonny, H. L., \& Kellogg, J. Mandalas as a measure of change in psychotherapy. American Journal of Art Therapy, 1977, 16, 126-128.

Butler, R. N. The life review: An interpretation of reminiscence in the aged. Psychiatry, 1963, 26, 65-76.

Butler, R. N., \& Lewis, M. I. Aging and mental health. St. Louis: The C. V. Mosby Company, 1977.

Davis, W., \& Klopfer, W. G. Issues in psychotherapy with the aged. Psychotherapy: Theory, Research and Practice, 1977, 14, 343347.

Dewdney, I. An art therapy program for geriatric patients. In Elinor Ulman \& Penny Dachinger (Eds.), Art therapy. New York: Schocken Books, 1975. 
Durkee, S. Artistic expression in later life. In Robert Kastenbaum (Ed.), New thoughts in old age. New York: Springer Publishing Company, Inc., 1964.

Eisdorfer, C., \& Lawton, M. P. (Eds.). The psychology of adult development and aging. Washington, D. C.: American Psychological Association, 1973.

Erikson, E. H. Childhood and Society (2nd ed.). New York: Norton, 1963.

Exner, J., Jr. Projective techniques. In Irving B. Weiner (Ed.), Clinical methods in psychology. New York: John Wiley \& Sons, 1976.

Fromm, E. Escape from freedom. New York: Holt, Rinehart \& Winston, 1941.

Gendlin, E. T., \& Olsen, L. The use of imagery in experiential focusing. Psychotherapy: Theory, Research and Practice, 1970, I, 221-223.

Goodenough, F. L. The measure of intelligence by drawings. Yonkerson-the-kudson, New York: World Book Company, 1926.

Gurland, B. J. A broad clinical assessment of psychopathology in the aged. In Carl Eisdorfer \& M. Powell Lawton (Eds.), The psychology of adult development and aging. Washington, D. C.: American Psychological Association, 1973.

Harms, E. The development of modern art therapy. Art Psychotherapy, $1975, \underline{2}, 189-193$.

Henry, W. E., \& Cumming, E. Personality development in adult and old age. Journal of Projective Techniques, 1959, 23, 383-390.

Hodnett, M. I. A broader view of art therapy. Art Psychotherapy, 1973, 1 , 75-79.

Honig, S. Art therapy used in treatment of schizophrenia. Art Psychotherapy, 1977, 4, 99-104.

Ingebretsen, R. Psychotherapy with the elderly. Psychotherapy: Theory, Research and Practice, 1977, 14, 319-332.

Jarvik, L. F., \& Cohen, D. A biobehavioral approach to intellectual changes with aging. In Carl Eisdorfer \& M. Powell Lawton (Eds.), The psychology of adult development and aging. Washington, D. C.: American Psychological Association, 1973.

Jones, N. E. Care of the aging: A new view. Psychotherapy: Theory, Research and Practice, 1977, 14, 379-385. 
Jourard, S. M. The transparent self. New York: D. Van Nostrand Company, 1971

Jung, C. G. Two essays on analytical psychology. New York: Pantheon, 1953.

Jung, C. The archetypes and the collective unconscious. In Vol. $9 i$ of The collected works of C. G. Jung. Princeton, New Jersey: Princeton University Press, 1969.

Jung, C. G. (Ed.). Man and his symbols. New York: Dell Publishing Co., Inc., 1977.

Kellogg, J., MacRae, M., Bonny, H. L., \& DiLeo, F. The use of the mandala in psychological evaluation and treatment. American Journal of Art Therapy, 1977, 16, 123-130.

Kivalo, A. Art therapy with children. Psychiatria Fennica (Finnish Psychiatry), 1978, 93-102.

Kramer, E. Art therapy in a children's community. Springfield, Illinois: C. C. Thomas, 1958.

Kramer, E. The problem of quality in art. In Elinor Ulman \& Penny Dachinger (Eds.), Art therapy. New York: Schocken Books, 1975.

Krasner, J. D. Loss of dignity--courtesy of modern science. Psythotherapy: Theory, Research and Practice, 1977, 14, 309-318.

Krech, D., Crutchfield, R. S., \& Livson, N. Elements of Psychology. New York: Alfred A. Knopf, 1974.

Lawton, M. P. Clinical psychology? In Carl Eisdorfer \& M. Powell Lawton (Eds.), The psychology of adult development and aging. Washington, D. C.: American Psychological Association, 1973.

Lindzey, G., Hall, C. S., \& Thompson, R. F. Psychology. New York: Worth Publishing Co., 1975.

Machover, K. Personality projection in the drawing of the human figure. Springfield, Illinois: Charles C. Thomas, 1949.

MacRae, M. The mandala as a therapeutic tool: A case study. American Journal of Art Therapy, 1977, 16, 130-134.

Manaster, A. Therapy with the "senile" geriatric patient. International Journal of Group Psychotherapy, 1972, 22, 250-257.

May, R. The courage to create. New York: W. W. Norton \& Company, Inc., 1978. 
McGee, J., \& Lakin, M. Social perspectives on psychotherapy with the aged. Psychotherapy: Theory, Research and Practice, 1977, 14, 333-342.

McNiff, S. A. A new perspective in group art therapy. Art Psychotherapy, 1973, I, 243-245.

Meyerhoff, H. Art as therapy in a group setting. American Journal of Art Therapy, 1977, 16, 135-144.

Musick, P. L. Primitive percepts and collective creativity. Art Psychotherapy, $1976,3,43-50$.

Naumburg, M. Schizophrenic art: Meaning in psychotherapy. Iondon: Heinemann, 1950.

Naumburg, M. An introduction to art therapy: Studies of the "free" art expression of behavior problem children and adolescents as a means of diagnosis and therapy. New York: Teachers College Press, 1973.

Neugarten, B. L., Havighurst, R. J., \& Tobin, S. S. The measure of life satisfaction. Journal of Gerontology, 1961, 16, 134-143.

Nouwen, H. J. M., \& Gaffney, w. J. Aging. Garden City, New York: Image Books, 1976.

Perkins, C. F., \& Wagemaker, H. Art therapy with a dialyzed schizophrenic. Art Psychotherapy, 1977, 4, 137-147.

Perls, F. S. Gestalt Therapy verbatim. California: Real People Press, 1969.

Pine, S. Fostering growth through art education, art therapy, and art in psychotherapy. In Elinor Ulman \& Penny Dachinger (Eds.), Art therapy. New York: Schocken Books, 1975.

Powers, P. S., \& Langworthy, J. Artwork: Another dimension in the treatment of psychiatric patients. Art Psychotherapy, 1978, 5. $71-79$.

Prados, M. The use of pictorial images in group therapy. American Journal of Psychotherapy, 1951, 5, 196-214.

Quinn, J. H. Ego-psychologically oriented art therapy. In Lois C. Dunlap (Ed.), Mental health concepts applied to nursing. New York: John wiley \& Sons, 1978.

Rhineberger, S. P. The role of the patient activities department in psychiatric care. New York: John Wiley \& Sons, 1978. 
Rhyne, J. The Gestalt art experience. Monterey, California: Brooks/ Cole Publishing Co., 1973.

Riegel, K. R. On the history of psychological gerontology. In Carl Eisdorfer \& M. Powell Lawton (Eds.), The psychology of adult development and aging. Washington, D. C.: American Psychological Association, 1973.

Robbins, A. A psychoanalytic prospective towards the interrelationship of the creative process and the functions of an art therapist. Art Psychotherapy, 1978, 1, 7-12.

Rogers, C. R. On becoming a person. Boston: Houghton Mifflin Company, 1961 .

Rogers, S. B. Contributions of dance therapy in a treatment program for retarded adolescents and adults. Art Psychotherapy, 1977, 4. 195-197.

Schultz, D. Growth psychology: Models of the healthy personality. New York: Van Nostrand Reinhold Company, 1977.

Shneidman, E. S. The Make-A-Picture Test. New York: Psychological Corporation, 1949 .

Shorr, J. E. Psychotherapy through imagery. New York: Intercontinental Medical Book Corporation, 1974.

Steidel, Y. Group painting as a means of self-expression and communication for mentally retarded persons: Three case histories. (2 volumes). Unpublished M. S. thesis, Portland State University, 1979.

Ulman, E. Art therapy: Problems of definition. In Elinor Ulman \& Penny Dachinger (Eds.), Art therapy. New York: Schocken Books, 1975.

Ulman, E., \& Dachinger, P. (Eds.). Art therapy. New York: Schocken Books, 1975.

Vaccaro, V. M. "The art of psychotics"--Another point of view. Art Psychotherapy, 1977, 4, 121-123.

Virshup, E. A compilation of feelings by right brain people in a left brain world. Los Angeles: The Guild of Tutors Press, 1978.

Vorbusch, H. J. The use of special art therapy method in schizophrenic patient groups. Confinia Psychiatry, 1977, 20, 185-194.

Williams, S., Tamura, T. A., \& Rosen, D. H. An outpatient art therapy group. Art Psychotherapy, 1977, 4, 199-214. 
Wilson, I. Theory and practice of art therapy with the mentally retarded. American Journal of Art Therapy, 1977, 16, 87-97.

Wittels, B. Jung, art therapy, and the psychotic patient. Art Psychotherapy, 1978, $5,115-121$.

Wood, V., Wylie, M. L., \& Shaefor, B. An analysis of short self-report measure of life satisfaction: Correlation with rater judgments. Journal of Gerontology, 1969, 24, 465-469.

Zeiger, B. L. Life review in art therapy with the aged. American Journal of Art Therapy, 1976, 15, 47-50.

Zubin, J. Foundations of gerontology: History, training, and methodology. In Carl Eisdorfer \& M. Powell Lawton (Eds.), The psychology of adult development and aging. Washington, D. C.: American Psychological Association, 1973. 
Here are sowe statewents abourt IIfe in general that people feel different ways about. Would you road each strtement on the list and if you agroe. with it, purt a check nark in the space under "AFPEE." If you do not agree with a statement, put a chock eark in the space under "DIShGRiE." If you are not are one wy or the other, put a chock nurk in the space inder "ip." plose be are to enower overy question an the list.

Meres Drsueras ?

1. As I grow older, things seen better then 1 . I thought they would be.

2. I hrve eotten nore of the broiks in 1ife 2 . then wost of the pecple I linow.

3. This is the dreariest tine of ay 1ife.

3.

4. I a just as buppy as when I was younger. 4 .

5. Iy life could be heppier then it is now. 5 .

6. These are the best years of ay life.

7. Hbst of the things I do ar boring or aroteonous.

8. I expect some interrestin and pleneme things to hypen to $m$ in the furarre.

9. The things I do are as interesting to ne as thay over were.

10. I feel old and sombet tirnd.

6.

7.

$$
\text { - }
$$

.

3.

.

6.

7.

8.

9.

.

10.

11. I feel ay are, but it does not bother m.

12.

-

12. well satisfled.

13. I would not chenge of past lifo even if I could.

14. Coupared to other people ay age, I've nde a lot of foolish dectsions in ity life.

15. Conpared to other people or ape, I anlie a good eqpenranco.

16. I have made plans for things I'Il bo coine a wanth or a yarr fro nor.

17. then I think back oror any 11fo, I didn't get nost of the ipportent things I mented.

18. Compered to other people, I get down in the dups too often.

23.

24.

15.

16.

27.
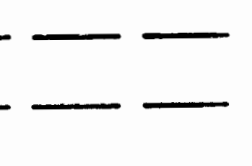

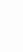




\section{APPENDIX B}

\section{INFORMED CONSENT}

$\mathbf{I .}$ agree to serve as a subject in the research project investigating life satisfaction among the elderly conducted by Phyllis McGraw. I understand that the study will involve answering questions; taking several tests; participating in social or art-related group activities; and doing a comprehensive life history. I understand that I will be given a description of the project after it is completed.

I understand there will be no physical, social, economic or other risks or discomforts, such as threat to dignity. Wile I understand the study may ask me questions about my life which may temporarily upset me, this will be only for a short period and Phyllis McGraw will assist me. I also understand that my name or identifying personal data will not be used except that some of the material may be developed into an anecdotal case study for research and educational purposes.

I understand that if I have any questions, I may discuss these with Mrs. McGraw of the Psychology Department at Portland State University.

It has been explained to me that the purpose of the study is to find out how different activities influence the quality of the life review process.

I may not receive any direct benefit from participating in this study, but my participation may help to increase knowledge which may benefit others in the future.

Mrs. McGraw has offered to answer any questions I may have about the study and what is expected of me in the study. I understand that I an free to withdraw from participation in this study at any time and that my participation will not affect any activities I pursue or receive at the Augustana Lutheran Church, Portland, Oregon.

I have read and understand the foregoing information.

Date: Signature

If you experience problems that are the result of participation in this study, please contact Richard streeter, Office of Graduate studies and Research, 105 Neuberger Hall, Portland State University, 229-3423. 


\section{APPENDIX C}

TWO-FACTOR MIXED DESIGN: REPEATED MEASURES ON ONE FACTOR*

\begin{tabular}{lccccc} 
Source & SS & df & MS & F & P \\
\hline Total & 678.80 & 59 & - & - & - \\
Between subjects & 618.60 & 29 & - & - & - \\
Conditions & 18.10 & 2 & 9.05 & .41 & $>.05$ \\
Error (b) & 600.50 & 27 & 22.24 & - & - \\
Within subjects & 60.00 & 30 & - & - & - \\
Trials & 1.66 & 1 & 1.66 & .89 & $>.05$ \\
Trials x conditions & 8.04 & 2 & 4.02 & 2.16 & $>.05$ \\
Error (w) & 50.30 & 27 & 1.86 & - & - \\
& & & &
\end{tabular}

$\mathbf{N}=30$

Group $\mathbf{n}=10$

*Differences between Pre- and Post-tests

Based on scores on the Life Satisfaction Index-A 


\section{APPENDIX D \\ CLARIFICATION OF THE PROBLEM}

It was discovered in this study that when the experimenter was a stranger in a group, people were reluctant to volunteer when a signed consent form was required. In fact, the mere presentation of a legal form caused many people to become suspicious and consequently they refused to listen to any possible benefits which might result from participation. Should anyone wish to replicate this study, he/she should consider establishing a rapport with intended subjects prior to requesting volunteers. 